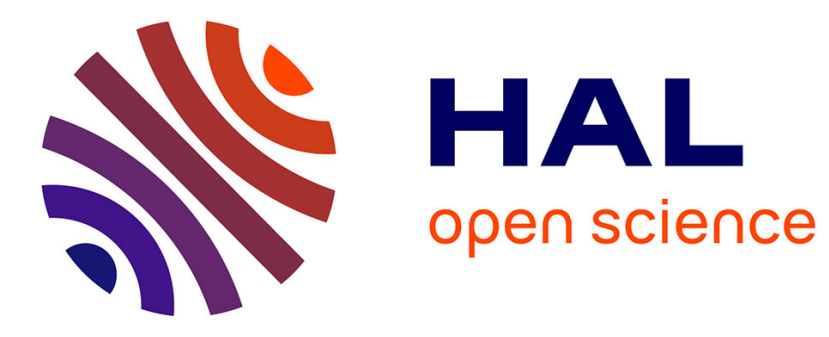

\title{
Counterion Effect on the Spin-Transition Properties of the Cation $[\mathrm{Fe}(\mathrm{btzx}) 3] 2+$ $($ btzx $=\mathbf{m}-$ Xylylenebis $($ tetrazole $)$ )
}

Manuel Quesada, Ferry Prins, Eckhard Bill, Huub Kooijman, Patrick Gamez, Olivier Roubeau, Anthony L. Spek, Jaap G. Haasnoot, Jan Reedijk

\section{To cite this version:}

Manuel Quesada, Ferry Prins, Eckhard Bill, Huub Kooijman, Patrick Gamez, et al.. Counterion Effect on the Spin-Transition Properties of the Cation $[\mathrm{Fe}(\mathrm{btzx}) 3] 2+(\mathrm{btzx}=\mathrm{m}-\mathrm{Xylylenebis}($ tetrazole $))$. Chemistry - A European Journal, 2008, 14 (28), pp. 8486-8499. 10.1002/chem.200800990 . hal00323792

\section{HAL Id: hal-00323792 https://hal.science/hal-00323792}

Submitted on 5 Oct 2017

HAL is a multi-disciplinary open access archive for the deposit and dissemination of scientific research documents, whether they are published or not. The documents may come from teaching and research institutions in France or abroad, or from public or private research centers.
L'archive ouverte pluridisciplinaire HAL, est destinée au dépôt et à la diffusion de documents scientifiques de niveau recherche, publiés ou non, émanant des établissements d'enseignement et de recherche français ou étrangers, des laboratoires publics ou privés. 
Counterion Effect on the Spin-Transition Properties of the Cation $\left[\mathrm{Fe}(\operatorname{btzx})_{3}\right]^{2+}(\mathbf{b t z x}=m$-Xylylenebis $($ tetrazole $))$

Manuel Quesada, ${ }^{[\mathrm{a}]}$ Ferry Prins, ${ }^{[\mathrm{a}]}$ Eckhard Bill, ${ }^{[\mathrm{b}]}$ Huub Kooijman, ${ }^{[\mathrm{c}]}$ Patrick Gamez, ${ }^{[\mathrm{a}]}$ Olivier Roubeau, ${ }^{[\mathrm{d}]}$ Anthony L. Spek, ${ }^{[\mathrm{c}]}{ }^{\mathrm{Jaap}}$ G. Haasnoot, ${ }^{[\mathrm{a}]}$ and Jan Reedijk ${ }^{[\mathrm{a}]}$

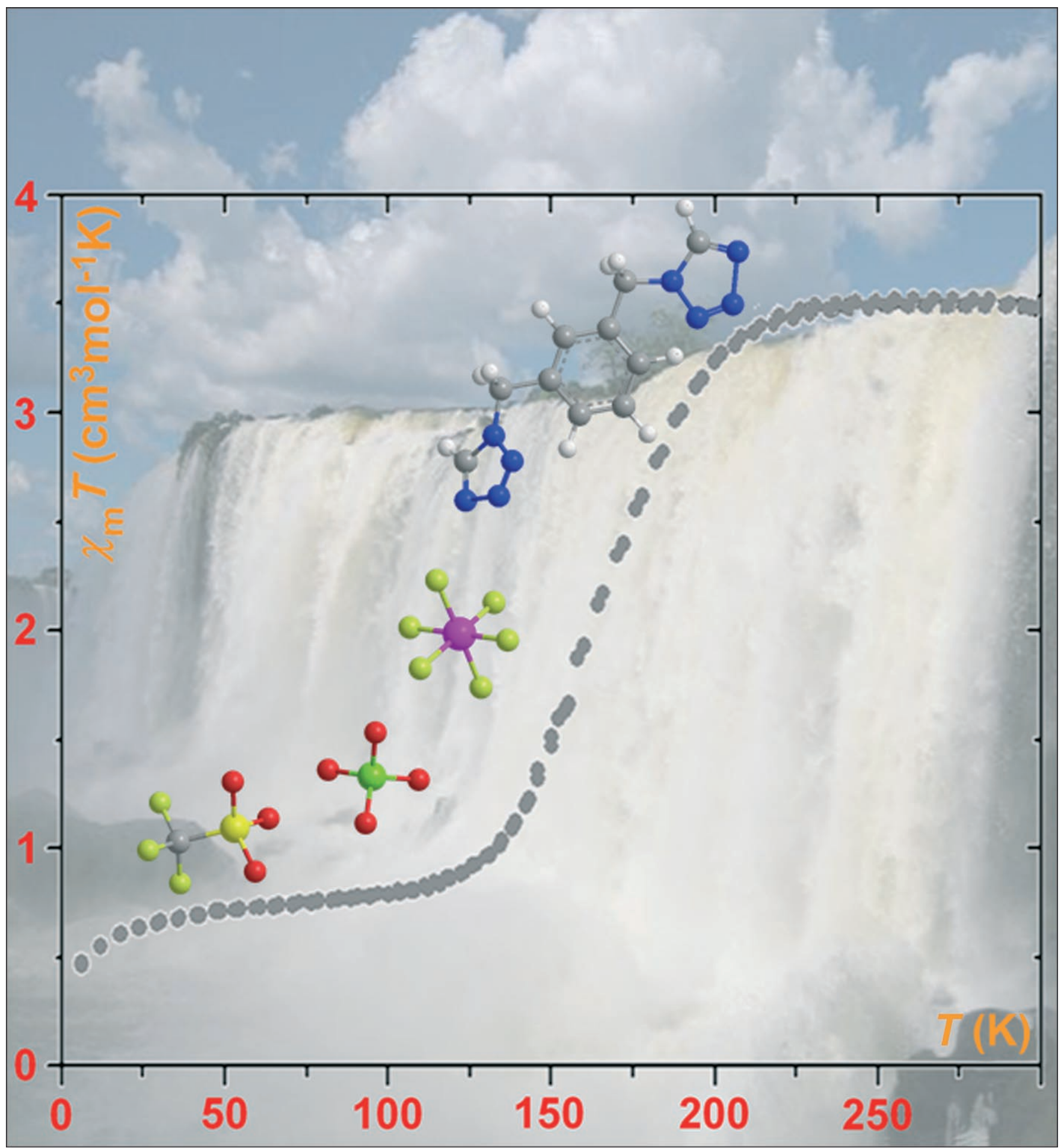




\begin{abstract}
The influence of the counteranion on the structure and the spintransition properties of original 1D bis(tetrazole) $\quad \mathrm{Fe}^{\mathrm{II}}$ systems, namely $\left[\mathrm{Fe}(\mathrm{btzx})_{3}\right] \mathrm{X}_{2} \quad\left(\mathrm{X}=\mathrm{PF}_{6}^{-}(\mathbf{1}), \mathrm{CF}_{3} \mathrm{SO}_{3}{ }^{-}\right.$ (2) and $\mathrm{ClO}_{4}^{-}(\mathbf{3})$; btzx $=m$-xylylenebis(tetrazole)) is studied. The X-ray crystal structures of compounds $\mathbf{1}$ and $\mathbf{2}$ are described in detail. These structures present a solvent molecule encapsulated within pockets formed by btzx
\end{abstract}

ligands along the 1D coordination chains. Compound $\mathbf{2}$ is shown to be the first structurally characterised alternating HS-LS 1D spin-transition system (HS = high spin, $\mathrm{LS}=$ low spin $).$ The magnetic susceptibility measurements of all three compounds are compared.

Keywords: anions $\cdot$ bis(tetrazole) iron $\cdot$ polymers $\cdot$ spin crossover
The degree of completion and the transition temperature are both drastically influenced by the counterion used, while surprisingly, the cooperative nature of the transition is not affected by the choice of counterion. Compounds $\mathbf{1}$ and $\mathbf{2}$ are further studied by Mössbauer spectroscopy and their distinct LIESST properties are compared.

\section{Introduction}

The rational design of highly efficient and specific functional materials is now a main area of research, as the so-called top-down approach is reaching its limits of miniaturisation. ${ }^{[1]}$ The bottom-up approach represents an exciting alternative, based on the idea that the miniaturisation limit of an electronic function is the molecule. Spin-crossover (SCO) systems fall in this category, and could work as molecular switches or memory storage devices. ${ }^{[2,3]}$ These materials, mostly coordination complexes of $\mathrm{d}^{4}$ to $\mathrm{d}^{7}$ transition metal ions and especially $\mathrm{Fe}^{\mathrm{II}}$, are able to undergo a low spin (LS) to high spin (HS) transition by means of an external stimulus. ${ }^{[4]}$ This entropy driven phenomenon ${ }^{[5]}$ is sometimes accompanied by a thermochromic effect, which makes these systems valuable for optical-storage devices.

The spin-transition phenomenon is strictly molecular, but its characteristics are dependent on the overall crystal lattice. The narrow range of ligand field strength for which a spin transition may be observed makes these systems sensitive, not only to the first coordination sphere, but also to the second coordination sphere. Entities such as counterions or

[a] Dr. M. Quesada, F. Prins, Dr. P. Gamez, Dr. J. G. Haasnoot, Prof. J. Reedijk

Leiden Institute of Chemistry, Gorlaeus Laboratories

Leiden University, P. O. Box 9502

2300 RA Leiden (The Netherlands)

Fax: $(+31) 71-5274671$

E-mail: p.gamez@chem.leidenuniv.nl haasnoot@chem.leidenuniv.nl

[b] Dr. E. Bill

Max-Planck-Institut für Bioanorganische Chemie Stiftstrasse 34-36, 45470 Mülheim an der Ruhr (Germany)

[c] Dr. H. Kooijman, Prof. Dr. A. L. Spek

Bijvoet centre of Bimolecular Research Crystal and Structural Chemistry, Utrecht University

Padualaan 8, $3584 \mathrm{CH}$ Utrecht (The Netherlands)

[d] Dr. O. Roubeau

Université Bordeaux 1

Centre de Recherche Paul Pascal-CNRS

115 avenue du dr. A. Schweitzer, 33600 Pessac (France)

Supporting information for this article is available on the WWW under http://dx.doi.org/10.1002/chem.200800990. lattice-solvent molecules may have a drastic effect on the spin-transition properties of the material. ${ }^{[4]}$ Bis(tetrazole)based coordination polymers of $\mathrm{Fe}^{\mathrm{II}}$ belong to this family of compounds showing spin-transition properties. ${ }^{[6]}$ Gradual to steep temperature-dependent magnetic responses have been reported with bis(tetrazole) compounds. ${ }^{[7]}$ The variation of the size of the spacer linking the two tetrazole rings has resulted in compounds with different dimensionality. ${ }^{[8-10]}$ The size, conformation and flexibility of the spacer all seem to have an important effect on the magnetic behaviour of the resulting materials. ${ }^{[11]}$ Weinberger and co-workers recently published a study on the relationship between the size of the alkyl spacer and the $T_{1 / 2}$ (temperature at which half of the metal centres are in LS states, the other half being in the HS state) and the optical properties of the complexes. ${ }^{[12]}$ An effect of the length of the spacer on the thermomagnetic and magneto-optical properties is expected, but a correlation with the parity (number of carbons) of the spacer has also been established. Further systematic studies are necessary to better understand the role played by each chemical piece constituting the metal-organic network.

In this respect, no study has yet been undertaken to try to understand the influence of the counterion on the spin-transition behaviour within a family of bis(tetrazole) ligands. This lack is mainly due to synthetic problems that arise when preparing coordination compounds from these ligands with different $\mathrm{Fe}^{\mathrm{II}}$ salts. The role of the counterion is to template the crystallisation process. Most importantly, the size of the counterion has an effect on the quality of the crystallisation. ${ }^{[12]}$ In addition, the exchange of counterions very often results in an annihilation of the SCO properties, resulting from slight structural variations able to modify the ligand-field strength or form a complete different structure. Consequently, its influence on the spin transition is very difficult to investigate. So far, the only report mentioning the preparation of $\mathrm{Fe}^{\mathrm{II}}$ spin-transition compounds with two different counterions involves the ligand btzb (btzb $=1,4$-bis(tetrazole-1-yl)butane). ${ }^{[8,13]}\left[\mathrm{Fe}(\mathrm{btzb})_{3}\right]\left[\mathrm{PF}_{6}\right]_{2}$ shows a twostep steep transition, while the perchlorate derivative shows a steep, incomplete transition, ${ }^{[13]}$ or a gradual one-step transition, ${ }^{[12]}$ suggesting two different phases. 
The compounds herein described are based on the btzx ligand, which bears two tetrazoles rings bridged by a spacer, namely $m$-xylene. So far such a rigid spacer has not been used, as all previously reported bis(tetrazole) ligands are based on aliphatic-chain linkers. The synthesis, characterisation and magnetic properties of a new series of compounds containing the cation $\left[\mathrm{Fe}(\mathrm{btzx})_{3}\right]^{2+}(\mathrm{btzx}=m$-xylylenebis(tetrazole)) and various anions, that is, $\mathrm{PF}_{6}{ }^{-}(\mathbf{1}), \mathrm{CF}_{3} \mathrm{SO}_{3}{ }^{-}$ (2), and $\mathrm{ClO}_{4}^{-}(3)$ are reported below. The crystal structures of $\mathrm{PF}_{6}{ }^{-}$and $\mathrm{CF}_{3} \mathrm{SO}_{3}{ }^{-}$derivatives are described in detail. We show that the use of a rigid linker maintains the overall structure when changing counterion, while it allows detailed discussion of the influence of the counterion on the structural, magnetic and photomagnetic properties.

\section{Results}

\section{Crystal structure descriptions}

$\left[\mathrm{Fe}(\mathrm{btzx})_{3}\right]\left[\mathrm{PF}_{6}\right]_{2} \cdot \mathrm{MeOH}(\mathbf{1})$ : The space group for compound 1 at 200 and $100 \mathrm{~K}$ is $P 63 / m$ (Table 1 ). Its structure is formed of coordination chains separated by $\mathrm{PF}_{6}{ }^{-}$ions that

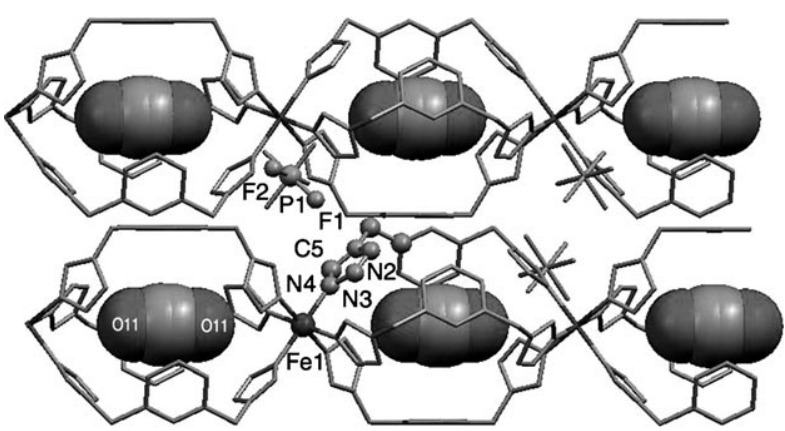

Figure 1. View of the X-ray crystal structure along the $b$ axis, showing the polymeric nature of compound $\mathbf{1}$. The disordered methanol molecules are represented in the space-filling mode.

the $\mathrm{Fe}-\mathrm{N}_{\mathrm{D}}$ distance is 2.001(3) $\AA$, which corresponds to a $7 \%$ decrease of the bond length upon the transition. The coordination sphere for the HS centres is characterised by a slightly distorted octahedron (set of angles N4-Fe1-N4; 90.48 and $89.52^{\circ}$ ), while the LS iron(II) centres exhibit a nearly regular octahedral geometry (set of angles N4-Fe1$\mathrm{N} 4 ; 90.13$ and $89.87^{\circ}$ ). The distortion parameter, $\Sigma$, for compound $\mathbf{1}$ is one of the smallest octahedral distortions in both, the HS and the LS states, for any previously reported bis(tetrazole) Fe-based spintransition (ST) compounds. ${ }^{[17]}$ $[\Sigma$ symbolises the sum of the deviations from $90^{\circ}$ of the 12 cis $\mathrm{N}-\mathrm{Fe}-\mathrm{N}$ angles.]

The bent conformation of the ligands results in the formation of a 1D polymer, extending along the $c$ axis. The $\mathrm{Fe}^{\mathrm{II}}$ centres are bridged by three ligands that adopt the same conformation, forming cages in which the disordered methanol molecules (no interactions) are trapped (Figure 1). The $\mathrm{Fe} \cdots \mathrm{Fe}$ separation along the polymer chains at $200 \mathrm{~K}$ is $11.397 \AA$, and is $11.205 \AA$ at $100 \mathrm{~K}$, while the

are not disordered, while a methanol molecule is crystallographically disordered between two positions (Figure 1), within cages along the chains. This disorder of the solvent molecule is observed at both temperatures. The $\mathrm{Fe}^{\mathrm{II}}$ metal ion is surrounded by six crystallographically related tetrazole rings that coordinate through the $\mathrm{N}_{\mathrm{D}}$ atom, forming an almost perfect octahedral environment (see Table 2). $\left[\mathrm{N}_{\mathrm{D}}\right.$ stands for nitrogen "donor atom", and represents the atom coordinated to the metal ion.] At $200 \mathrm{~K}$, all $\mathrm{Fe}-\mathrm{N}_{\mathrm{D}}$ distances amount to 2.160(4) $\AA$, in the expected range for an $\mathrm{Fe}^{\mathrm{II}} \mathrm{HS}$ centre (Table 2). ${ }^{[4]}$ This bond length is close to those observed in previously reported bis(tetrazole)-based compounds, ${ }^{[8,14,15]}$ and slightly shorter than $\mathrm{Fe}-\mathrm{N}_{\mathrm{D}}$ bonds found for mononuclear tetrazole-based compounds. ${ }^{[16]}$ At $100 \mathrm{~K}$, interpolymeric $\mathrm{Fe} \cdots \mathrm{Fe}$ distance is 10.679 and $10.543 \AA$ at these respective temperatures. The most important structural changes caused by the spin transition are found along the $c$ axis (see Table 1). Surprisingly, there is no significant modification of the structural arrangement of the ligand.

As for other bis(tetrazole)-based 1D polymers, ${ }^{[10,18]}$ the particular packing of the chains generates hollow spaces in which the counterions are located (see Figure 2). Each polymer chain is separated from its six neighbours by six $\mathrm{PF}_{6}^{-}$ ions (see Figure 2). Each $\mathrm{PF}_{6}{ }^{-}$ion is shared by three polymers, resulting in the expected $\mathrm{Fe} / \mathrm{PF}_{6}{ }^{-}$ratio of $1: 2$. The distance separating the counterions from the metal centres is $5.166 \AA$ for the HS state, and decreases by $0.068 \AA$ upon switching to the LS state (see Table 4, below). All the 
Table 2. Selected interatomic distances $[\AA]$ and angles $\left[^{\circ}\right]$ for compound 1 at 200 and $100 \mathrm{~K}$. Symmetry operations: $i=-y, x-y, z ; \mathrm{k}=-x+y,-x$, $z ; \mathrm{m}=-x,-y,-z ; \mathrm{o}=y,-x+y,-z ; \mathrm{q}=x-y, x,-z$.

\begin{tabular}{lcc}
\hline & $200 \mathrm{~K}$ & $100 \mathrm{~K}$ \\
\hline Fe1-N4 (i, k, m, o, q) & $2.160(4)$ & $2.0011(29)$ \\
N4-Fe1-N4i & $90.48(17)$ & $90.13(11)$ \\
N4-Fe1-N4k & $90.48(18)$ & $90.13(11)$ \\
N4-Fe1-N4m & 180.00 & 180.00 \\
N4-Fe1-N4o & $89.52(17)$ & $89.87(11)$ \\
N4-Fe1-N4q & $89.52(18)$ & $89.87(11)$ \\
N4i-Fe1-N4k & $90.5(2)$ & $90.13(13)$ \\
N4i-Fe1-N4m & $89.52(17)$ & $89.87(11)$ \\
N4i-Fe1-N4o & $180.0(3)$ & $180.00(16)$ \\
N4i-Fe1-N4q & $89.5(2)$ & $89.87(13)$ \\
N4k-Fe1-N4m & $89.52(18)$ & $89.87(11)$ \\
N4k-Fe1-N4o & $89.5(2)$ & $89.87(13)$ \\
N4k-Fe1-N4q & $180.0(3)$ & $180.00(20)$ \\
N4m-Fe1-N4o & $90.48(17)$ & $90.13(11)$ \\
N4m-Fe1-N4q & $90.48(18)$ & $90.13(11)$ \\
N4o-Fe1-N4q & $90.5(2)$ & $90.13(13)$ \\
\hline
\end{tabular}
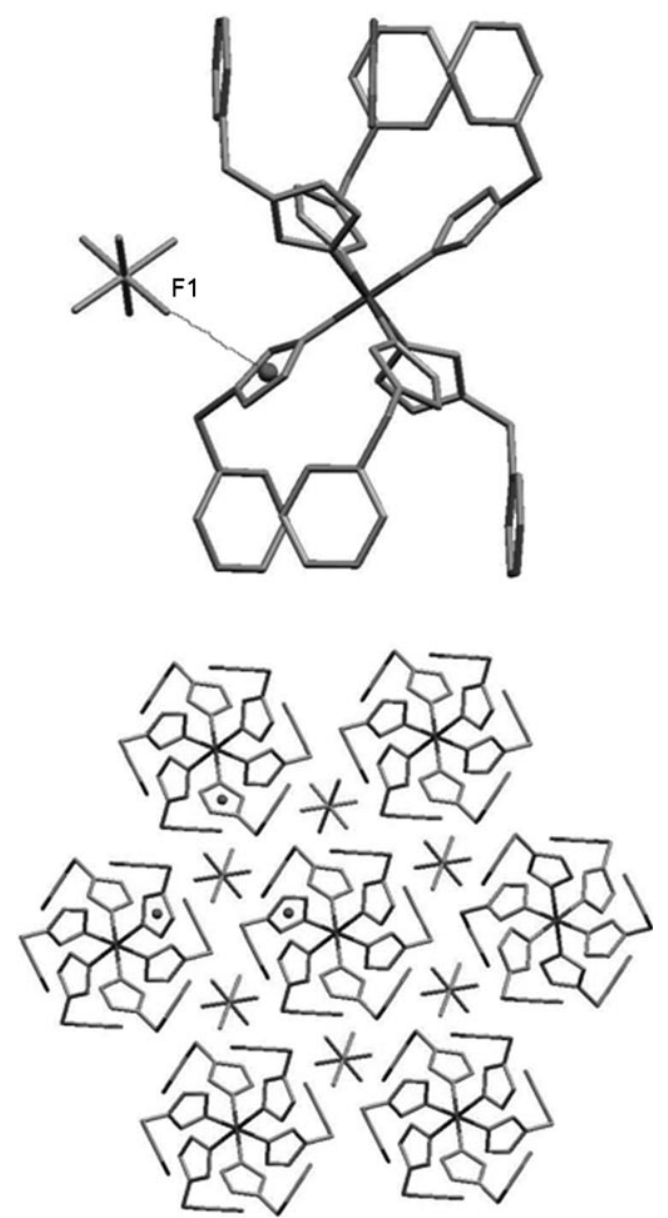

Figure 2. Top: Representation of the iron coordination sphere of compound 1 showing the anion- $\pi$ interactions (distance F1 $\cdots$ centroid of the tetrazole ring $=3.137 \AA$ ). Bottom: View of the X-ray crystal structure along the $c$ axis.

anions are lying in the plane formed by the $\mathrm{Fe}^{\mathrm{II}}$ centres, and each of them interacts through anion $-\pi$ contacts with three different chains (Figure 2). No solvent molecules are present between the polymeric chains in the crystal lattice. However, solvent molecules are trapped inside the cages formed by three ditopic ligands (see Figure 1). No intermolecular interactions between the polymer chains are observed. The solidstate structure is most likely imposed by the coordination of the ligands to the metal ions.

$\left[\mathrm{Fe}(\mathrm{btzx})_{3}\right]\left[\mathrm{CF}_{3} \mathrm{SO}_{3}\right]_{2} \cdot \mathrm{CH}_{3} \mathrm{CN}$ (2): At $320 \mathrm{~K}$ compound 2 crystallises in the same space group as the hexafluoridophosphate derivative $\mathbf{1}$, namely the $P 63 / m$ hexagonal space group. The structure is very similar to that of compound $\mathbf{1}$. The $\mathrm{Fe}-\mathrm{N}_{\mathrm{D}}$ distance is $2.163 \AA$ (Table 3 ), which suggests an

Table 3. Selected interatomic distances [̊] and angles [ $\left.{ }^{\circ}\right]$ for 2 at $320 \mathrm{~K}$. Symmetry operations: $\mathrm{d}=1-y,-1+x-y, z ; \mathrm{f}=2-x+y, 1-x, z ; \mathrm{h}=2-x$, $-y, 1-z ; \mathrm{j}=1+y, 1-x+y, 1-z ; 1=x-y,-1+x, 1-z$.

\begin{tabular}{lclr}
\hline Fe1-N1 (d, f, h, j, l) & $2.163(13)$ & N1d-Fe1-N1j & $180.0(8)$ \\
N1-Fe1-N1d & $90.0(5)$ & N1d-Fe1-N1L & $90.1(6)$ \\
N1-Fe1-N1j & $90.1(5)$ & N1f- Fe1-N1h & $90.1(5)$ \\
N1-Fe1-N1h & 180.00 & N1f -Fe1-N1j & $90.1(6)$ \\
N1-Fe1-N1f & $90.0(5)$ & N1f -Fe1-N1L & $180.0(9)$ \\
N1-Fe1-N1L & $90.1(5)$ & N1h-Fe1-N1j & $90.0(5)$ \\
N1d-Fe1-N1f & $90.0(6)$ & N1h-Fe1-N1L & $90.0(5)$ \\
N1d-Fe1-N1h & $90.1(5)$ & N1j-Fe1-N1L & $90.0(6)$ \\
\hline
\end{tabular}

$\mathrm{Fe}^{\mathrm{II}}$ high-spin centre at this temperature. The coordination sphere is close to octahedral $\left(\Sigma=0.6^{\circ}\right)$ with $\mathrm{N}-\mathrm{Fe}-\mathrm{N}$ angles of $90.05^{\circ}$ and $89.95^{\circ}$ (see Table S1 in the Supporting Information). The triflate anions are not disordered, while the only solvent molecules present in the crystal lattice have two different spatial orientations inside the benzene cages (Figure 2). The solvent-to-metal distance is $4.095 \AA$, which is around $0.5 \AA$ shorter than the corresponding length observed for compound $\mathbf{1}$. This short distance is most likely due to the longer length of the acetonitrile molecule (compare to methanol), which is confined inside the host cavity, therefore forcing closer interactions with the metal ion. The bent conformation of the ligand creates the same 1D polymeric structure extended along the $c$ axis. The $\mathrm{Fe} \cdots \mathrm{Fe}$ intrapolymeric distance is $11.613 \AA$, thus $0.216 \AA$ longer than the one observed for compound $\mathbf{1}$. The interpolymeric distance is $10.954 \AA$, which is also somewhat longer than the one in compound 1. In both cases, the planes of the benzene rings form an angle of $60^{\circ}$ and the distance of the solvent molecules to these planes is comparable. The distance that separates the anion from the metal centre is $5.287 \AA$ (see Table 4), slightly longer than the corresponding one in compound 1. To define the spatial arrangement of the anion in the crystal structure, the angle of the $\mathrm{C}-\mathrm{S}$ axis with respect to the $c$ axis (axis along which the polymer extends) is used. In the present case, the $\mathrm{C}-\mathrm{S}$ axis is parallel to the $c$ axis.

As the temperature is lowered, the compound undergoes a structural phase transition to the less symmetric $P \overline{3}$ space group. At $170 \mathrm{~K}$, at which the transition of $\left[\mathrm{Fe}(\mathrm{btzx})_{3}\right]-$ $\left[\mathrm{CF}_{3} \mathrm{SO}_{3}\right]_{2} \cdot \mathrm{CH}_{3} \mathrm{CN}(2)$ is finished, the compound now exhib- 
Table 4. HS/LS anion-to-metal distances, anion- $\pi$ separations, $\Sigma$ (distortion parameter reflecting the deformation of the octahedral coordination environment) and cone angles for compound 1, and for the four independent $\mathrm{Fe}^{\mathrm{II}}$ centres of compound $\mathbf{2}$

\begin{tabular}{|c|c|c|c|c|c|}
\hline \multicolumn{2}{|l|}{$T[\mathrm{~K}]$} & $\begin{array}{l}\text { Anion-metal } \\
\text { distance }[\AA]\end{array}$ & $\begin{array}{l}\text { Ttz-anion } \\
\text { interaction }[\AA]\end{array}$ & $\Sigma\left[^{\circ}\right]$ & $\begin{array}{l}\text { Cone } \\
\text { angle }{ }^{[\mathrm{b}]}\left[{ }^{\circ}\right]\end{array}$ \\
\hline \multicolumn{6}{|c|}{ compound $\mathbf{1}$} \\
\hline \multicolumn{2}{|l|}{200} & $5.166,5.146$ & 3.137 & 5.82 & 85.67 \\
\hline \multicolumn{2}{|c|}{$\begin{array}{l}100 \\
\text { compound } \mathbf{2}\end{array}$} & $5.098,5.088$ & 3.089 & 1.56 & 85.88 \\
\hline \multicolumn{2}{|l|}{320} & 5.287 & 3.111 & 0.6 & 85.29 \\
\hline \multicolumn{6}{|l|}{$170^{[\mathrm{a}]}$} \\
\hline & Fe1 HS & $5.135,4.384$ & $2.998,3.385$ & 11.73 & $81.58 / 86.3$ \\
\hline & $\mathrm{Fe} 2 \mathrm{HS}$ & $4.905,4.896$ & $2.968,3.214$ & 21.47 & $83.65 / 86.16$ \\
\hline & $\mathrm{Fe} 3 \mathrm{HS}$ & 4.852 & 3.086 & 1.92 & 83.13 \\
\hline & $\mathrm{Fe} 4 \mathrm{HS}$ & 5.369 & none & 11.64 & 87.39 \\
\hline \multicolumn{6}{|l|}{$100^{[\mathrm{a}]}$} \\
\hline & Fe1 HS & $5.063,4.319$ & $2.944,3.32$ & 10.89 & $81.55 / 86.23$ \\
\hline & $\mathrm{Fe} 2 \mathrm{LS}$ & $4.867,4.898$ & 2.9613 .190 & 10.14 & $84.41 / 87.12$ \\
\hline & $\mathrm{Fe} 3 \mathrm{HS}$ & 4.815 & 3.005 & 3.24 & 82.77 \\
\hline & $\mathrm{Fe} 4 \mathrm{LS}$ & 5.343 & none & 12.12 & 88.43 \\
\hline
\end{tabular}

[a] Compound $\mathbf{2}$ has four crystallographically independent centres which are shown separately. [b] The cone angle is the angle formed by the centroids of two tetrazoles of the same side of the plane formed by the iron(II) atoms.

its a more intricate structure. Nevertheless, a comparable overall picture is maintained; the compound is still constituted of $1 \mathrm{D}$ polymeric chains that extend along the $c$ axis. The crystal turned out to be a merohedral twin, with a twofold rotation axis parallel to the $c$ axis as the twin operation. The compound crystallises in the $P \overline{3}$ space group and, possesses two unique chains: 1) chain 1 lies at a crystallographic 3 axis (symmetry $C_{3}$ ) and contains the $\mathrm{Fe} 1$ and $\mathrm{Fe} 2$ centres (Figure 3 ); 2) chain 2 lies on a crystallographic -3 axis (symmetry $S_{6}$ ) and contains the ions labelled as $\mathrm{Fe} 3$ and $\mathrm{Fe} 4$ (Figure 3). The twofold axis of the twin operation is parallel to the 3 and -3 axes.

Chain $1-F e 1$ and $F e 2$ centres: Chain 1 is formed by two independent iron centres, namely $\mathrm{Fe} 1$ and $\mathrm{Fe} 2$, which are both coordinated by six tetrazole rings and are alternatingly connected by btzx ligands. At $170 \mathrm{~K}$, the $\mathrm{Fe}-\mathrm{N}$ bond lengths for $\mathrm{Fe} 1$ are 2.208(4) (Fe1-N18) and 2.178(4) $\AA$ (Fe1-N1), and those for $\mathrm{Fe} 2$ are 2.192(4) (Fe2-N8) and 2.196(4) $\AA$ $(\mathrm{Fe} 2-\mathrm{N} 11)$. These values are all in the range expected for HS Fe ${ }^{\mathrm{II}}$ centres (see Table $\mathrm{S} 1$ in the Supporting Information). ${ }^{[4]}$ At $100 \mathrm{~K}$, the $\mathrm{Fe}-\mathrm{N}$ distances for $\mathrm{Fe} 2$ amount to 2.061(3) (Fe2-N8) and 2.059 (3) $\AA$ (Fe2-N11), corresponding to a decrease of $6 \%$. These distances are in the range for LS Fe ${ }^{\mathrm{II}}$ centres ${ }^{[4]}$ therefore, their shortening reflects the $\mathrm{HS} \rightarrow \mathrm{LS}$ transition occurring in $\mathrm{Fe} 2$ (see below). In contrast, $\mathrm{Fe} 1$ shows practically no variation of the $\mathrm{Fe}-\mathrm{N}$ coordination bond lengths at $100 \mathrm{~K}$, indicating that this metal centre remains HS throughout the entire temperature range. The distortion of the octahedral geometry can be estimated with the parameter $\Sigma$. Both the $\mathrm{Fe} 1$ and the $\mathrm{Fe} 2$ ions are closer to the ideal octahedron $\left(\Sigma=0^{\circ}\right)$ at $100 \mathrm{~K}$ than at $170 \mathrm{~K}$ (see Table 4). At $170 \mathrm{~K}$, the octahedral coordination sphere is significantly more distorted for $\mathrm{Fe} 2$, as compared to $\mathrm{Fe} 1$. At lower temperatures, the distortion in both centres is compa-

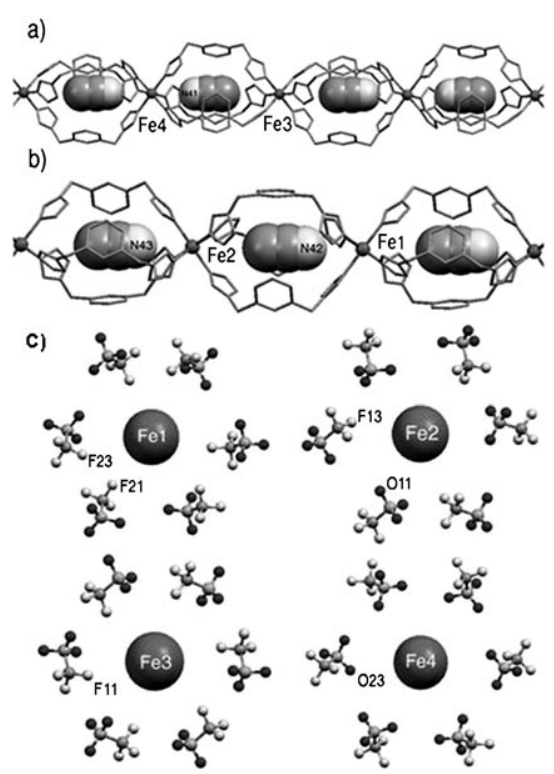

Figure 3 . View along the $b$ axis of the two crystallographically independent chains, showing the orientation of the trapped solvent molecules in a) Chain 2 and b) Chain 1 of compound 2. c) View of the different anionsurroundings for each of the four independent $\mathrm{Fe}^{\mathrm{II}}$ centres present in compound $\mathbf{2}$, all depicted independently and viewed along the $c$ axis.

rable. These $\Sigma$ values contrast with those of the previous related 1D polymeric compound, that is, $\left[\mathrm{Fe}(\mathrm{btzx})_{3}\right]-$ $\left[\mathrm{PF}_{6}\right]_{2} \cdot \mathrm{CH}_{3} \mathrm{OH}(\mathbf{1})$, which shows $\Sigma$ values closer to 0 (reflecting a less important distortion) both in the HS and in the LS states (see Table 4).

The metal centres are enclosed by six triflate counterions, each shared by two other metal centres, thus resulting in the expected triflate/Fe ratio of 2:1. The spatial arrangement of these counterions differs depending on the metal centre. As seen in Figure 3, two different types of arrangements for the counterions around $\mathrm{Fe} 1$ are observed. Both types have their $\mathrm{CF}_{3}$ group close to the metal ion, with $\mathrm{Fe}-\mathrm{F}$ distances of $4.384 \AA(\mathrm{F} 21 \cdots \mathrm{Fe} 1)$ and $5.135 \AA(\mathrm{F} 23 \cdots \mathrm{Fe} 1)$. The torsion angle formed by the $\mathrm{C}-\mathrm{S}$ axis and the $c$ axis is $-22.90^{\circ}$ and $142.07^{\circ}$, which at low temperatures become $-27.34^{\circ}$ and $138.64^{\circ}$ respectively. These torsion angles are far from $0^{\circ}$, the value observed for the structure determined at $320 \mathrm{~K}$. These counterions are alternating around the metal centre (see Figure 3).

The counterions surrounding the $\mathrm{Fe} 2$ ions are organised in a different way. As for Fe1, there are two different spatial dispositions for the counterions around $\mathrm{Fe} 2$, which are alternatingly distributed. In this case, the two distinct types of triflate ions are clearly differentiated, because one of them has its $\mathrm{CF}_{3}$ group closer to the metal centre $\mathrm{Fe} 2$, while for the other one, the $-\mathrm{SO}_{3}$ function is adjacent to $\mathrm{Fe} 2$. The corresponding distances are $4.905 \AA$ for $\mathrm{Fe} 2 \cdots \mathrm{O}_{1} 1_{\mathrm{SO}_{3}}$, and $4.896 \AA$ for $\mathrm{Fe} 2 \cdots \mathrm{F}_{1} 3_{\mathrm{CF}_{3}}$ (Table 4). The torsion angles of their $\mathrm{C}-\mathrm{S}$ axis with respect to the polymeric axis are of 130.24 and $55.83^{\circ}$, respectively. The former undergoes a negligible change of orientation in the LS state, while the latter experiences a change of about $2^{\circ}$. When the temperature decreas- 
es, only the $\mathrm{Fe} 1$ centre experiences a significant variation of the metal $\cdots$ counterion distances, with a shortening of the $\mathrm{F} 21 \cdots \mathrm{Fe} 1$ and $\mathrm{F} 23 \cdots \mathrm{Fe} 1$ distances by more than $0.5 \AA$. The peculiar crystal packing of $1 \mathrm{D}$ bis(tetrazole)-based polymers is responsible for this proximity of the counterion to the metal centre. ${ }^{[17]}$ These close contacts give rise to strong anion-tetrazole interactions (Figure 4), observed for the
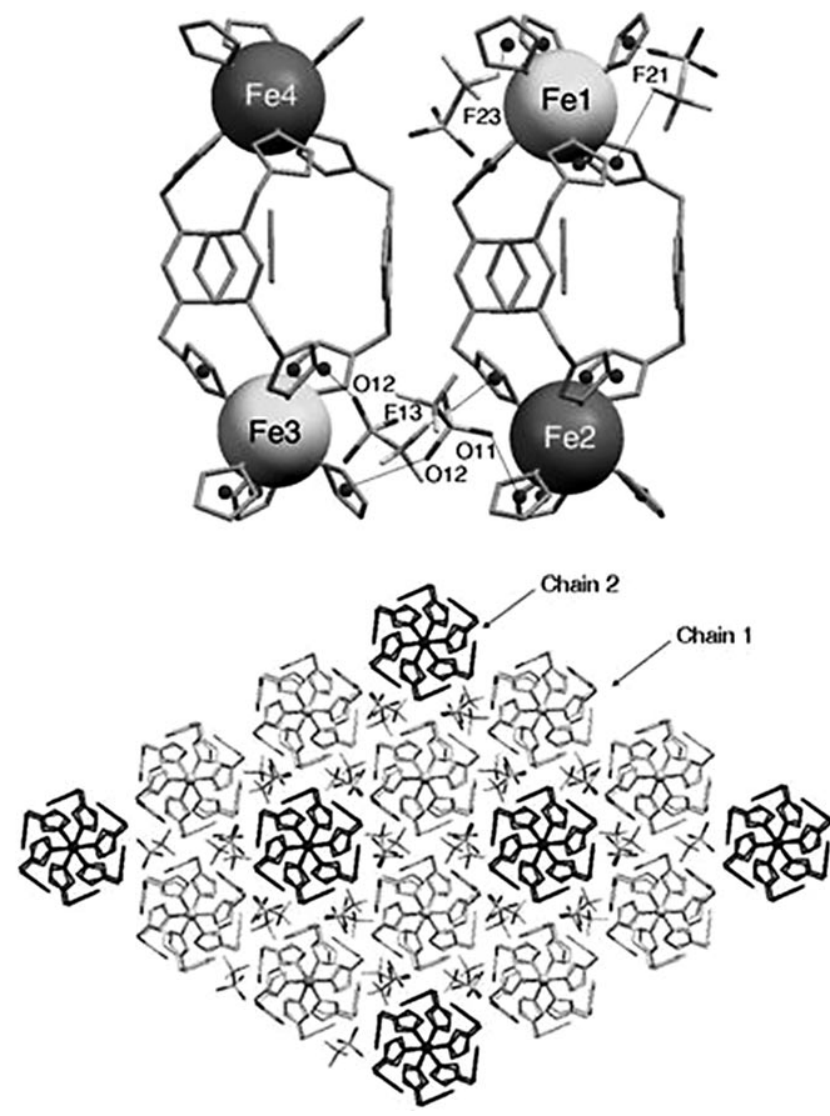

Figure 4. Top: Anion- $\pi$ interactions occurring in chain 1 and chain 2 in compound 2. All tetrazoles involved in anion- $\pi$ interactions are marked with their centroids. Bottom: View of the packing along the $c$ axis for compound 2.

anions closest to $\mathrm{Fe} 1$ and $\mathrm{Fe} 2$ (Table 4). The deviation of the anion-tetrazole (centroid) distance between the structure measured at $170 \mathrm{~K}$, and the one measured at $100 \mathrm{~K}$ is only significant for the anion closest to Fe1.

The solvent molecules trapped in the cages formed by three bridging btzx ligands present some differences with respect to the structure solved at $320 \mathrm{~K}$. Each cavity contains one solvent molecule, and all these acetonitrile molecules are orientated in the same direction (head-to-tail, namely with the nitrogen atom alternatingly pointing to $\mathrm{Fe} 1$ and Fe2 (see Figure 3). These acetonitrile molecules do show weak solvent $-\pi$ interactions with the coordinated tetrazole rings, and are therefore not disordered in the cage, in contrast to the methanol molecules in 1. TGA analyses for both compounds show that these solvent molecules are tightly trapped in the cages, as they cannot be released before the decomposition of the material.

Chain 2-Fe3 and Fe4 centres: The chain 2 is also constituted of two independent $\mathrm{Fe}^{\mathrm{II}}$ centres, that is, $\mathrm{Fe} 3$ and $\mathrm{Fe} 4$, which are alternately connected by three btzx ligands (Figure 3). Similarly to chain 1 , the coordination sphere for both $\mathrm{Fe} 3$ and $\mathrm{Fe} 4$ is formed by six tetrazoles rings, but all tetrazoles are here crystallographically related. As a result, chain 2 has a higher symmetry than chain 1 . The metal-toligand bond lengths for $\mathrm{Fe} 3(\mathrm{Fe} 3-\mathrm{N} 21)$ and Fe4 (Fe4-N28) at $170 \mathrm{~K}$ are 2.178 (4) and 2.185(4) A, respectively (Table S1 in the Supporting Information). These bonds are slightly shorter than those observed for chain 1 , but they are still within the range for $\mathrm{HS} \mathrm{Fe}^{\mathrm{II}}$ systems. ${ }^{[4]}$ At $100 \mathrm{~K}$, the metalto-ligand bond lengths decrease (the values observed are $6.7 \%$ lower) for $\mathrm{Fe} 4$, indicating a $\mathrm{HS} \rightarrow \mathrm{LS}$ transition (Table S1 in the Supporting Information). ${ }^{[4]}$ As for the Fe1 ions found in chain 1 , the metal-to-ligand bond lengths remains practically unchanged for $\mathrm{Fe} 3\left(\mathrm{Fe}-\mathrm{N}_{\mathrm{tz}}=2.182 \AA\right)$, illustrative of a HS centre. At $170 \mathrm{~K}$, the octahedral distortion for $\mathrm{Fe} 4$ is comparable to that observed for $\mathrm{Fe} 1$ and $\mathrm{Fe} 2 . \mathrm{Fe} 3$ instead shows an almost perfect regular octahedral geometry (see Table 4), close to that observed for both compounds 2 at $320 \mathrm{~K}$ and 1. Surprisingly, the low-temperature structure (LS state) reveals slightly more distorted coordination spheres for both $\mathrm{Fe} 3$ and $\mathrm{Fe} 4$, while more symmetric, or less distorted coordination spheres are expected for LS compared to the HS centres.

In chain 2, six counterions "surround" each $\mathrm{Fe}^{\mathrm{II}}$ centre, and each anion is shared by two adjacent metal ions. The counterions are regularly arranged around $\mathrm{Fe} 3$ and $\mathrm{Fe} 4$, in contrast to the two different spatial arrangements observed for $\mathrm{Fe} 1$ and $\mathrm{Fe} 2$ (see Figure 3). The torsion angles between the $\mathrm{C}-\mathrm{S}$ axis and the $c$ axis for $\mathrm{Fe} 3$ are -64.66 and $-115.35^{\circ}$ and vary by $1.88^{\circ}$ in the LS state. For Fe4 the torsion angles are -156.09 and $-23.91^{\circ}$ in the HS state and are modified by $1.4^{\circ}$ at $100 \mathrm{~K}$. The $\mathrm{Fe} 3 \cdots \mathrm{F} 11_{\mathrm{CF}_{3}}$ distance is $4.852 \AA$ and the $\mathrm{Fe} 4 \cdots \mathrm{O} 23_{\mathrm{SO}_{3}}$ distance is $5.369 \AA$. F11 also "interacts" with $\mathrm{Fe} 2$, while the $\mathrm{O} 23$ atom also interacts with $\mathrm{Fe} 1$; accordingly, the iron pairs $\mathrm{Fe} 1 / \mathrm{Fe} 4$ and $\mathrm{Fe} 2 / \mathrm{Fe} 3$ share the same counterions (Figure 4). The distances do not vary significantly with the temperature for both metal centres forming chain 2 . This observation suggests that the variation noted for $\mathrm{Fe} 1$ (chain 1) is due to a rearrangement of the spatial orientation of the counterion (see torsion angles), and not to a displacement. Anion-tetrazole interactions are only observed for

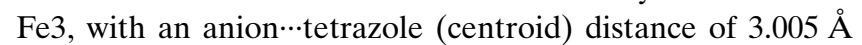
(Figure 4). Remarkably, Fe4 does not show this type of interactions, which may be related to the solvent disposition in the host cavities (see below).

As for chain 1, chain 2 also contains acetonitrile molecules in its cages formed by the three bridging btzx ligands. However, the acetonitrile molecules are arranged here in a headto-head manner (see Figure 5). Consequently, they are always pointing with their N41 atoms towards the Fe4 ions, interacting with the coordinated tetrazoles by means of solvent $-\pi$ interactions. The N41-centroid distance is $3.275 \AA$, 


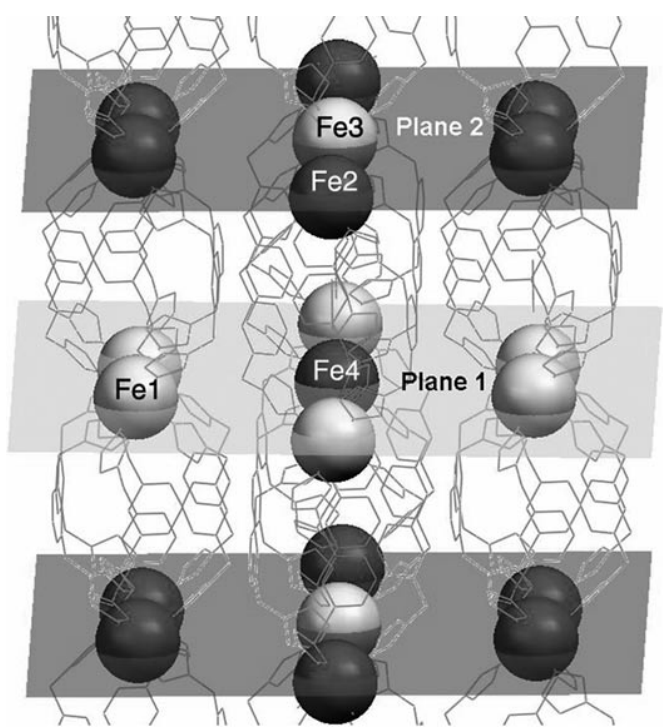

Figure 5. View of the HS-LS pattern observed for compound 2 at $100 \mathrm{~K}$ $(\mathrm{LS}=$ dark grey, $\mathrm{HS}=$ light grey)

which is longer than those observed in the other chain. $\mathrm{Fe} 4$ possesses two acetonitrile molecules very close to the first coordination sphere. The resulting increased electron density at the metal centre may explain the lack of anion- $\pi$ interactions for $\mathrm{Fe} 4$.

Crystal packing: The crystal packing of $\left[\mathrm{Fe}(\mathrm{btzx})_{3}\right]-$ $\left[\mathrm{CF}_{3} \mathrm{SO}_{3}\right]_{2} \cdot \mathrm{CH}_{3} \mathrm{CN}$ (2) is similar to that previously observed for other bis(tetrazole)-based 1D polymers. ${ }^{[17]}$ In Figure 4 (bottom), a chain $1 /$ chain 2 ratio of $2: 1$ is clearly evidenced. Chain 2 is surrounded by six chain 1 units, and each chain 1 is shared by three chain 2 units. The asymmetry of the chains and the spatial position of the counterions lead to a less symmetrical crystal packing, by comparison with the one of compound 1. The different tilting of the tetrazole rings, and the disparate spatial arrangements of the counterions are clearly visible in Figure 4 (bottom). The alignment of the polymeric chains generates planes with the iron(II) ions and the triflate counterions, which are separated by the cages formed by the btzx ligands.

The solid-state structure of compound 2 at $100 \mathrm{~K}$ presents an unusual crystal packing (Figure 5). As mentioned above, only one of the two crystallographically independent $\mathrm{Fe}^{\mathrm{II}}$ centres of each chain undergoes the spin transition. This particular situation results in the first example of a 1D chain exhibiting the unusual HS-LS pattern, typically observed for dinuclear entities. ${ }^{[19]}$ Polymeric spin-crossover materials, such as the known $\left[\mathrm{Fe}(\text { btrz })_{3}\right]\left[\mathrm{ClO}_{4}\right]_{2}($ btrz $=$ bis $($ triazole $))$ or $\left\{\mathrm{Fe}(\mathrm{pmd})\left[\mathrm{Ag}(\mathrm{CN})_{2}\right]\left[\mathrm{Ag}_{2}(\mathrm{CN})_{3}\right]\right\}$, do present the same type of pattern. ${ }^{[20,21]}$ In the present case, the $\cdots$ HS-LS-HS $\cdots$ alternation observed in the chains does not produce full HS or LS planes. In fact, the spin-transition (ST) centres of chain 1 share the same plane (plane2) with the non-ST centres of chain2, and vice versa (plane1). This arrangement in fact produces the peculiar packing depicted in Figure 5. Thus in plane1, each ST $(\mathrm{Fe} 4)$ centre is surrounded by six non-ST
(Fe1) centres, whereas in plane2, the non-ST (Fe3) ion is surrounded by six ST $(\mathrm{Fe} 2)$ centres.

$\left[\mathrm{Fe}(\mathrm{btzx})_{3}\right]\left[\mathrm{ClO}_{4}\right]_{2} \cdot \mathrm{CH}_{3} \mathrm{CN}(3)$ : The reaction conditions described above were used to prepare $\left[\mathrm{Fe}(\mathrm{btzx})_{3}\right]$ $\left[\mathrm{ClO}_{4}\right]_{2} \cdot \mathrm{CH}_{3} \mathrm{CN}(\mathbf{3})$. In contrast to the compounds $\mathbf{2}$ and $\mathbf{1}$, suitable single crystals of compound $\mathbf{3}$ could not be obtained, and thus the solid-state structure is not available. The IR and Elemental analyses suggest that compound $\mathbf{3}$ is structurally related to the previous two compounds. Considering that all the structural asymmetry observed for compound $\mathbf{2}$ is due to the triflate anions, the structure of compound $\mathbf{3}$ is expected to be comparable to that of compound 1. Unfortunately, no accurate structural information could be obtained from X-ray powder diffraction analysis, due to the poor crystallinity of the material. Nevertheless, the main structural features observed for the previous compounds most likely are also present in $\mathbf{3}$. Therefore, it is assumed this compound is composed of $1 \mathrm{D}$ polymeric chains, which presumably pack in a similar manner to compound $\mathbf{1}$.

Bulk magnetic properties and the LIESST effect: Magnetic susceptibility measurements were performed on samples of 1-3, in the temperature range 6-300 K, under an applied magnetic field of $1000 \mathrm{G}$ (see Figure 6). Complex 1 shows a gradual spin transition centred at $T_{1 / 2}=160 \mathrm{~K}$. At room temperature, the $\chi_{\mathrm{m}} T$ value is $3.5 \mathrm{~cm}^{3} \mathrm{molK}^{-1}$. This value remains constant until $210 \mathrm{~K}$, at which the transition gradually sets in, extending over more than $100 \mathrm{~K}$. The $\chi_{\mathrm{m}} T$ value then remains constant at $0.5 \mathrm{~cm}^{3} \mathrm{~mol} \mathrm{~K}^{-1}$ and finally decreases at very low temperatures, due to the zero-field splitting of remaining $\mathrm{HS} \mathrm{Fe}^{\mathrm{II}}$ centres. The residual high-spin fraction at low temperatures would correspond to $14 \%$ (see Mössbauer section below) of the total amount of $\mathrm{Fe}^{\mathrm{II}}$ atoms. Complex 2 shows a comparable behaviour. The transition is centred at $T_{1 / 2}=110 \mathrm{~K}$, with a lower completion compared to compound 1. The $\chi_{\mathrm{m}} T$ value at room temperature is about $3.5 \mathrm{~cm}^{3} \mathrm{~mol} \mathrm{~K}^{-1}$. At $146 \mathrm{~K}, \chi_{\mathrm{m}} T$ starts to gradually decrease

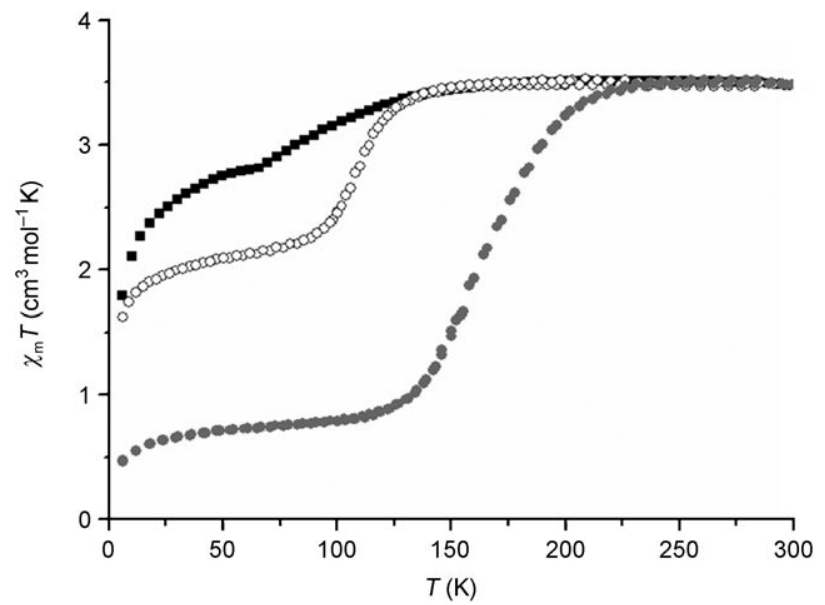

Figure 6. Plots of $\chi_{\mathrm{m}} T$ versus $T$ for compounds $\mathbf{1}\left(\mathrm{PF}_{6}\right.$, full circles), 2 $\left(\mathrm{CF}_{3} \mathrm{SO}_{3}\right.$, empty circles $)$ and $\mathbf{3}\left(\mathrm{ClO}_{4}\right.$, filled squares $)$. 
until $80 \mathrm{~K}$, at which a $\chi_{\mathrm{m}} T$ value of $2.2 \mathrm{~cm}^{3} \mathrm{molK}^{-1}$ is reached. In this case, the transition corresponds to $40 \%$ of the iron(II) centres, thus indicating a $60 \%$ residual highspin fraction at low temperatures. For compound $\mathbf{3}$, the transition is centred at $T_{1 / 2}=90 \mathrm{~K}$, involving only $20 \%$ of the iron centres. At very low temperatures, $\chi_{\mathrm{m}} T$ decreases as a result of the zero-field splitting of the remaining $\mathrm{HS} \mathrm{Fe}^{\mathrm{II}}$ ions. The completeness of the transitions for compound $\mathbf{3}$ is dependent on both the cooling rate and the quality of the sample (see Supporting Information). Indeed, the low temperature at which it occurs gives a dominant role to kinetics, which are slowed down, and to ZFS effects.

The magnetic behaviour of compounds $\mathbf{1}$ and $\mathbf{2}$ is in agreement with their structural features. For compound 1, the remnant HS fraction at low temperatures can be assigned to structural defects, like the extremities of the polymers. In triazole-based compounds, the remnant HS fraction at low temperatures is used to estimate the length of the polymeric 1D chains. ${ }^{[22,23]}$ For instance, in compound $\mathbf{1}$, the $\mathrm{Fe}^{\mathrm{II}}$ centres at the end of the polymeric chains are most likely coordinated by solvent molecules or non-bridging btzx ligands. As these "end-centres" remain HS, and taking into account that coordinated btzx ligands would create a favourable crystal field to produce $\mathrm{ST} \mathrm{Fe}^{\mathrm{II}}$ centres (like the "in-chain" ST centres), it is therefore expected that methanol molecules are completing the coordination spheres of the terminal $\mathrm{Fe}^{\mathrm{II}}$ ions (see Mössbauer section below). For compound $\mathbf{2}$, the incompleteness of the transition is also in agreement with its structural features. As mentioned above, in phase-II $(P \overline{3}$ phase, typically below $290 \mathrm{~K})$ only two out of four crystallographically independent $\mathrm{Fe}^{\mathrm{II}}$ centres present undergo the spin transition, while the other two remain HS. The transition temperature is $40 \mathrm{~K}$ lower than the one observed for $\mathbf{1}$, but the slope of the curve remains practically identical. Hence, the cooperativity seems not to be affected by the change of counterion.

Compound $\mathbf{3}$ exhibits a very incomplete transition, hampered by its low temperature of occurrence resulting in kinetics and ZFS to have dominant effects on the bulk magnetic properties. As mentioned earlier, this completeness is to a certain extent dependent on the cooling rate ${ }^{[24]}$ and on the sample preparation (see Supporting Information). ${ }^{[25]}$ Samples which have been obtained by rapid precipitation usually exhibit lower percentages of transition centres, while more crystalline samples show slightly higher values (see Figure S2 in the Supporting Information). The cooling rate also influences this value, although its effect is smaller, compared to the sample preparation (amorphous $v s$. crystalline). Accordingly, if the temperature is kept at $120 \mathrm{~K}$ for about $22 \mathrm{~h}$, only a negligible decrease of the $\chi_{\mathrm{m}} T$ value is detected. Hence, most of the incompleteness observed for compound $\mathbf{3}$ is independent of the sample preparation and/or the cooling rate. The incompleteness is apparently caused by an inherent structural impossibility for the compound to achieve a regular network in which all metallic centres are ST. A structural change occurring during the transition may also justify this incompleteness as seen for compound $\mathbf{2}$.
LIESST (light induced excited spin state trapping) ${ }^{[26]}$ measurements have been performed on compounds $\mathbf{1}$ and $\mathbf{2}$. Compound $\mathbf{1}$ is not excited to the metastable HS state upon irradiation at $530 \mathrm{~nm}$ at $10 \mathrm{~K}$. In contrast, compound 2 can be trapped at low temperatures in its HS metastable state. ${ }^{[26]}$ As shown in Figure 7, compound 2 not only shows LIESST, but also exhibits LITH (light induced thermal hysteresis ${ }^{[27,28]}$ behaviour (see Figure S3 in Supporting Information). This unambiguous behaviour suggests the presence of cooperative interactions between the metal centres (see the Discussion).

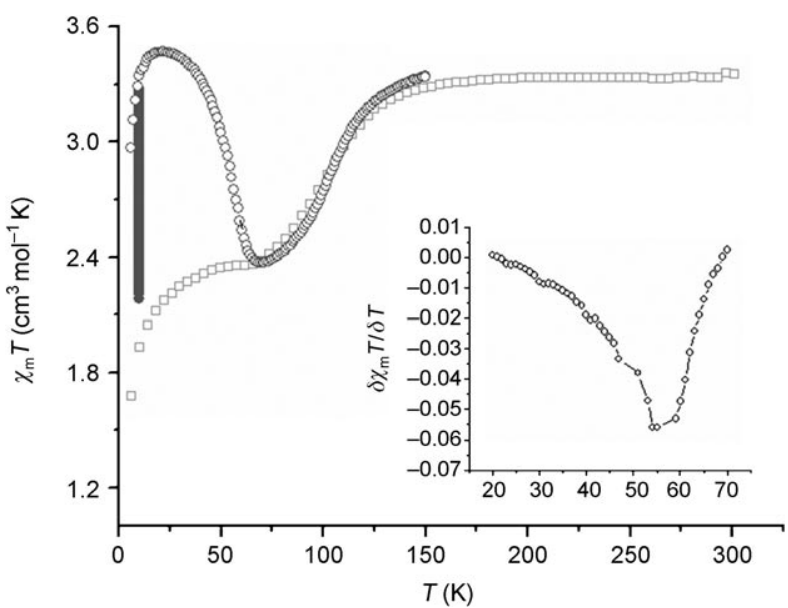

Figure 7. Plot of experimental $\chi_{\mathrm{m}} T$ versus $T$ (squares) and temperature dependence of the product $\chi_{\mathrm{m}} T$ after LIESST (circles), in the 6-300 K range for compound 2 . The inset shows the derivative of the product $\chi_{\mathrm{m}} T$ with a $T($ LIESST $)=54 \mathrm{~K}$.

Mössbauer spectroscopy: The Mössbauer spectrum at $80 \mathrm{~K}$ for compound $\mathbf{1}$ reveals a predominant single line with isomer shift $\delta=0.56 \mathrm{~mm} \mathrm{~s}^{-1}$, typical for a $\mathrm{LS} \mathrm{Fe}{ }^{\mathrm{II}}$ centre and a smaller quadrupole doublet characteristic of $\mathrm{HS} \mathrm{Fe}^{\mathrm{II}}$ centres $\left(\delta=1.21 \mathrm{~mm} \mathrm{~s}^{-1}, \Delta E_{\mathrm{Q}}=3.46 \mathrm{~mm} \mathrm{~s}^{-1}, 10 \%\right.$ relative intensity, see Table 5 and Figure 8 ). The spectrum at $110 \mathrm{~K}$ is practically identical with minor variations on the intensities of the two signals (Figure 8). An additional doublet, characteristic of $\mathrm{HS} \mathrm{Fe}{ }^{\mathrm{II}}$ centres, appears at $175 \mathrm{~K}$ (isomer shift $\delta=$ $1.14 \mathrm{~mm} \mathrm{~s}^{-1}$; quadrupole splitting $\Delta E_{\mathrm{Q}}=0.90 \mathrm{~mm} \mathrm{~s}^{-1}, 31 \%$ relative intensity) with a proportional decrease in intensity of the main LS signal. This new signal can thus be assigned to the transition of the iron centres from the LS to the HS state. At this temperature, also a very asymmetric doublet is observed, which is typical of $\mathrm{Fe}^{\mathrm{III}}$ centres, probably due to the partial oxidation of the sample $\left(\delta=0.34 \mathrm{~mm} \mathrm{~s}^{-1}, \Delta E_{\mathrm{Q}}=\right.$ $\left.0.47 \mathrm{~mm} \mathrm{~s}^{-1}, 6 \%\right)$. The asymmetry of the lines is caused by intermediate spin relaxation, which is typical of half-integer systems $(S=5 / 2)$. At room temperature, the LS signal has completely disappeared and the HS doublet is the main signal observed, which accounts for $74 \%$ of the iron centres in the compound. The signal assigned to the $\mathrm{Fe}^{\mathrm{III}}$ impurity increases in relative intensity, probably due to a more favourable Debye-Waller factor at higher temperatures. The 
Table 5. Mössbauer data for compounds 1 and 2.

\begin{tabular}{|c|c|c|c|c|c|}
\hline$T[\mathrm{~K}]$ & $\Delta E_{\mathrm{Q}}\left[\mathrm{mm} \mathrm{s}^{-1}\right]$ & $\delta\left[\mathrm{mm} \mathrm{s}^{-1}\right]$ & $\mathrm{FWHM}^{[\mathrm{a}]}$ & Area [\%] & Assignment \\
\hline \multicolumn{6}{|c|}{ compound $\mathbf{1}$} \\
\hline \multirow[t]{3}{*}{297} & 3.19 & 1.10 & 0.28 & 9 & HS (end chain) \\
\hline & 0.88 & 1.06 & 0.24 & 4 & HS (main chain) \\
\hline & 0.77 & 0.48 & $0.40 / 1.14^{[\mathrm{b}]}$ & 17 & $\mathrm{Fe}^{\mathrm{III}}$ \\
\hline \multirow[t]{4}{*}{175} & 0 & 0.5 & 0.34 & 51 & LS \\
\hline & 3.38 & 1.18 & 0.33 & 12 & HS (end chain) \\
\hline & 0.90 & 1.14 & 0.26 & 31 & HS (main) \\
\hline & 0.47 & 0.34 & $0.40 / 1.14^{[\mathrm{b}]}$ & 6 & $\mathrm{Fe}^{\mathrm{III}}$ \\
\hline \multirow[t]{2}{*}{110} & 0 & 0.56 & 0.40 & 89 & $\mathrm{~L}$ \\
\hline & 3.46 & 1.21 & 0.34 & 11 & HS (end chain) \\
\hline \multirow[t]{2}{*}{80} & 0 & 0.56 & 0.39 & 90 & LS \\
\hline & 1.212 & 3.48 & 0.27 & 10 & HS (end chain) \\
\hline \multicolumn{6}{|c|}{ compound $\mathbf{2}$} \\
\hline \multirow[t]{4}{*}{297} & 3.25 & 1.13 & 0.22 & 7 & HS (phase-II/end chain) \\
\hline & 1. 24 & 1.07 & 0.29 & 42 & HS (phase-II/main chain) \\
\hline & 0.91 & 1.07 & 0.29 & 4 & HS (phase-I/main chain) \\
\hline & 2.38 & 1.17 & 0.37 & 7 & HS (phase-I/end chain) \\
\hline \multirow[t]{4}{*}{175} & 3.13 & 1.25 & 0.54 & 12 & HS (phase-II/end chain) \\
\hline & 1.25 & 1.14 & 0.36 & 77 & HS (phase-II/main chain) \\
\hline & 0.36 & 1.14 & 0.28 & 9 & HS (impurity) \\
\hline & 0.57 & 0.07 & 0.30 & 2 & LS \\
\hline \multirow[t]{4}{*}{110} & 3.09 & 1.26 & 0.63 & 6 & HS (phase-II/end chain) \\
\hline & 1.34 & 1.17 & 0.38 & 1 & HS (phase-II/main chain) \\
\hline & 0.30 & 1.16 & 0.28 & 10 & HS (impurity) \\
\hline & 0.08 & 0.57 & 0.30 & 24 & LS \\
\hline \multirow[t]{4}{*}{80} & 3.19 & 1.25 & 0.53 & 14 & HS (phase-II/end chain) \\
\hline & 1.39 & 1.18 & 0.37 & 6 & HS (phase-II/main chain) \\
\hline & 0.26 & 1.18 & 0.28 & 1 & HS (impurity) \\
\hline & 0.58 & 0.12 & 0.30 & 40 & LS \\
\hline
\end{tabular}

[a] Full width at half maximum. [b] The doublet was asymmetrically broadened; the numbers indicate FWHM of the low-energy line/high-energy line.

HS signal observed at all previous temperatures is still present at room temperature. From these spectra, several conclusions can be made. First, the spin transition is observed and its temperature agrees with that determined by magnetic susceptibility measurements. Second, the sample contains ferric impurities, most likely resulting from the partial oxidation of the $\mathrm{Fe}^{\mathrm{II}}$ ions. Third, the presence of a second HS doublet could be related to the end of the polymeric chains, as proposed above. Based on this last assumption, the remaining HS fraction at low temperatures corresponds to about $9 \%$ (considering that the $\mathrm{Fe}^{\mathrm{III}}$ is still present), thus suggesting a chain length of approximately 30 metal centres.

Compound $\mathbf{2}$ is a more intricate system than $\mathbf{1}$. The Mössbauer spectra were recorded at 297, 170, 110 and $80 \mathrm{~K}$ (Figure 9). The spectrum recorded at $297 \mathrm{~K}$ reflects the structural phase transition in compound 2 (see above), as two different phases are clearly visible at this temperature. Indeed, the two main signals correspond to the $\mathrm{HS} \mathrm{Fe}^{\mathrm{II}}$ centres of the two different phases, while the smaller peaks can be assigned to the corresponding end-chains (as above for compound 1). From this spectrum it appears that the different $\mathrm{Fe}^{\mathrm{II}}$ centres of the trigonal phase (phase-II) are not distinguishable by Mössbauer spectroscopy. At $175 \mathrm{~K}$, the spectrum presents only one main HS signal, as indicated by its quadrupole splitting and isomer shift values (see Table 5). This observation confirms that the two previous signals (spectrum recorded at $297 \mathrm{~K}$ ) were due to the structural phase transition, which is completed at $170 \mathrm{~K}$ (see above). A very small peak is noticed, which indicates the beginning of the $\mathrm{HS} \rightarrow \mathrm{LS}$ transition for some of the $\mathrm{Fe}^{\mathrm{II}}$ centres (see Table 5 for the corresponding IS and QS values). The second doublet signal $\left(\delta=1.14 \mathrm{~mm} \mathrm{~s}^{-1}\right.$, $\Delta E_{\mathrm{Q}}=0.36 \mathrm{~mm} \mathrm{~s}^{-1}, 2 \%$ relative intensity, see Table 5 and Figure 8) has an isomer shift, which characterises a HS centre, while its quadrupole splitting is ascribed to a LS centre. This signal can only be assigned to an impurity of a highly symmetrical $\mathrm{Fe}^{\mathrm{II}} \mathrm{HS}$ species. When the temperature of measurement is decreased to $110 \mathrm{~K}$, the intensity of the LS signal increases at the expense of the main HS doublet. As expected, the other two peaks remain constant. Finally, the spectrum at $80 \mathrm{~K}$ illustrates the HS/LS ratio in compound 2 once the spin transition is completed. Only $40 \%$ of the iron centres experience the HS $\rightarrow$ LS, the remaining $60 \%$ exhibiting a high spin state.

\section{Discussion}

Pinpoint on the structural characteristics of $\left[\mathrm{Fe}(\mathrm{btzx})_{3}\right]-$ $\left[\mathrm{CF}_{3} \mathrm{SO}_{3}\right]_{2} \cdot \mathrm{CH}_{3} \mathrm{CN}$ : The intricate crystal structure of compound 2 observed at $170 \mathrm{~K}$ (phase-II) is a result of a structural phase transition occurring at room temperature. Above room temperature, this compound presents a more symmetrical structural phase, the features of which are comparable to those of compound $\mathbf{1}$. Indeed, both compounds 1 and $\mathbf{2}$ in phase-I crystallise in the trigonal space group P63/ $m$, have similar cell dimensions and even the same physical crystal appearance (see Table 1). The cone angle, the octahedral distortion and the anion-to-metal distances are almost identical (see Table 4). However, compound 1 shows an almost complete spin transition when the temperature is decreased, while for compound 2 only $50 \%$ of the iron(II) centres change to the LS state. This different behaviour suggests that the non-occurrence of the transition for half of the iron(II) centres is due to structural changes caused by the phase transition observed for compound $\mathbf{2}$. The resultant four crystallographically independent iron(II) centres of compound $\mathbf{2}$ in phase-II possess very similar coordination environments, but disparate magnetic behaviours. Therefore, subtle differences in the coordination spheres of the metallic 


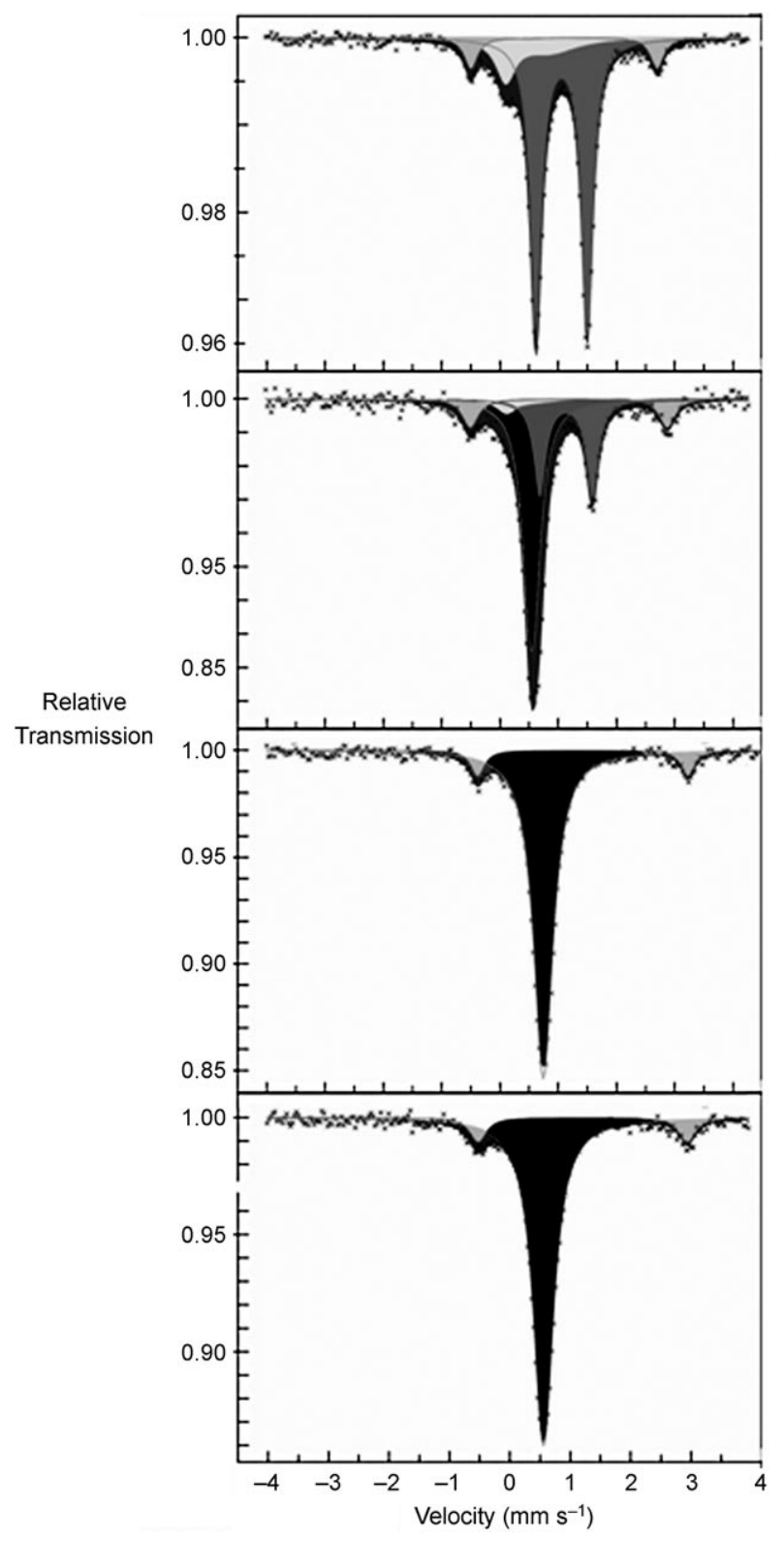

Figure 8. Mössbauer spectra for compound 1. From top to bottom: 297, 175,110 and $80 \mathrm{~K}$. Parameters are given in Table 5.

centres or, minor but key structural variations due to the crystal packing, may play a crucial role in the overall magnetic behaviour.

The alternate distribution of the LS and HS centres results in the first $1 \mathrm{D}$ polymeric chain showing the typical HS-LS pattern observed for dinuclear species. ${ }^{[29,30]}$ A remarkable difference between the phases-I and -II of compound 2 and all bis(tetrazole)-based 1D ST polymers (including compound $\mathbf{1}$ ) is the comparatively lower symmetry of its solid-state structure. The asymmetric nature of the $\mathrm{CF}_{3} \mathrm{SO}_{3}{ }^{-}$ions (in contrast to $\mathrm{BF}_{4}^{-}$or $\mathrm{PF}_{6}{ }^{-}$), associated with their spatial disposition in the crystal lattice (see crystal structure descriptions), is responsible for the overall asymmetry of the network. Indeed, many particular structural

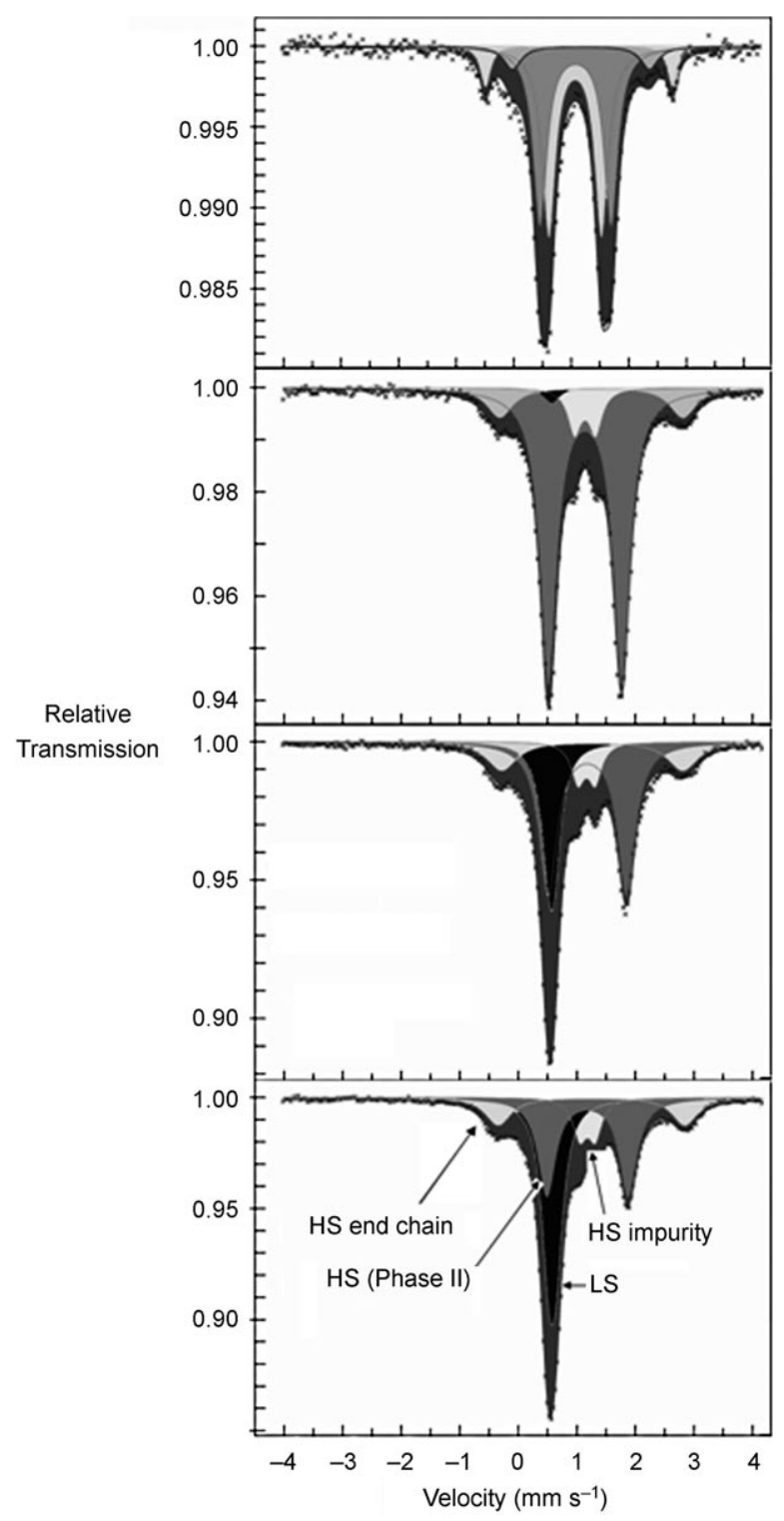

Figure 9. Mössbauer spectra for compound 2. From top to bottom: 297, 175,110 and $80 \mathrm{~K}$. Parameters are given in Table 5.

features of $\mathbf{2}$ can be related to its counterion. The existence of two distinct planes (plane 1 containing the $\mathrm{Fe} 1$ and $\mathrm{Fe} 4$ ions, and plane 2 the $\mathrm{Fe} 2$ and $\mathrm{Fe} 3$ centres) is evidently caused by the different disposition adopted by the counterions in each of these planes (see Figure S1 in the Supporting Information). The position of the triflates in the lattice also influences their association with the tetrazole moieties through anion $-\pi$ interactions, and vice versa. As a result of these triflate $\cdots$ tetrazole contacts, the coordination angle of the tetrazole rings (cone angle) is affected. The proximity of the counterion to the metal centre sterically and electronically influences the ligand-field strength of the btzx ligands, and thus the magnetic properties of the corresponding iron ions (see cone angles). Furthermore, the orientation of the solvent molecules in the cavities is most likely determined by the interactions of the counterions with the tetrazole 
rings, resulting in the polarisation of the host cages. All these structural characteristics, induced by the triflate anions, apparently lead to a unique magnetic behaviour.

Dinuclear $\mathrm{Fe}^{\mathrm{II}}$ complexes are known to be the most common molecular systems that exhibit the HS-LS pattern, which is observed in the present polynuclear compound. ${ }^{[29-31]}$ The occurrence of a two-step transition for these materials is due to the stabilisation of the intermediate HS-LS domain. ${ }^{[32,33]}$ Interestingly, the first two-step spin-transition phenomenon was observed in a mononuclear entity, that is, $\left[\mathrm{Fe}(\mathrm{pic})_{3}\right] \mathrm{Cl}_{2} \cdot \mathrm{EtOH} \quad$ (pic=2-picolylamine). ${ }^{[34]} \quad$ Subsequent studies have proven that the solid-state structure of this complex is formed by $1 \mathrm{D}$ supramolecular chains through intermolecular interactions that stabilise the HS-LS pattern. ${ }^{[35]}$ Similarly, in phase-II of compound 2, a HS-LS domain is observed; however, in this case, the metallic centres are part of a polymer generated by means of coordination bonds.

Much effort has been devoted to the study and comprehension of the HS-LS domain formation. For dinuclear complexes where the two $\mathrm{Fe}^{\mathrm{II}}$ centres are identical, it has been proposed that, in order to observe this supramolecular phenomenon, the enthalpic energy of the HS-LS pairs should be lower than half the sum of the enthalpic energies of the HS and LS states. ${ }^{[32,33]}$ In addition, intermolecular interactions are required to stabilise the HS-LS domain formation. ${ }^{[32]}$ In the case of compound 2 phase-II, HS-LS pairs are likely to be even more stabilised than in $[\mathrm{Fe}$ (pic) $)_{3} \mathrm{Cl}_{2} \cdot \mathrm{EtOH}$ as a result of the stronger coordinative interactions, and therefore only the plateau is observed, without a second step. On the other hand, the presence of different crystallographic iron(II) centres is probably the main reason for their different magnetic behaviour. Structural features (intra- and/or intermolecular supramolecular interactions) may directly affect the spin-transition properties. ${ }^{57} \mathrm{Fe}$ Mössbauer measurements show no distinction between the different iron(II) centres when they have the same electronic state (LS or HS), suggesting a structural/sterical origin for the difference in magnetic behaviour (and not an electronic one) ${ }^{[36]}$ As mentioned above, the spatial arrangement of the triflate anions in the lattice is the main factor influencing most of the other structural characteristics. From the structural data of other 1D spin-transition bis(tetrazole)-based compounds, ${ }^{[17]}$ it is well established that this family of ST materials usually experience a tilting of the coordinated tetrazole rings upon the transition (this tilting is defined by the (tetrazole-centroid)- $\mathrm{N}_{\mathrm{D}}$-Fe angles). In the present case, this change of angle is hampered by the disposition of the anions for $\mathrm{Fe} 1$ and $\mathrm{Fe} 3$ (see below). Consequently, the anion significantly affects the characteristics of the spin-transition curves of the $\left[\mathrm{Fe}(\mathrm{btzx})_{3}\right]^{2+}$ ions.

The effect of the counterion on the spin-transition properties: As mentioned above, the effect of the counterion on the magnetic properties of bis(tetrazole)-based spin-transition materials has not yet been investigated thoroughly. Indeed, the only ST cation reported ${ }^{[8,13]}$ with two different anions, namely $\mathrm{ClO}_{4}^{-}$and $\mathrm{PF}_{6}{ }^{-}$, is $\left[\mathrm{Fe}(\mathrm{btzb})_{3}\right]^{2+}$. It is known that the crystallinity of bis(tetrazole)-based compounds is dependent on the anion used. ${ }^{[12]}$ The role of the anion in this type of materials is to act as a template for the generation of the cationic polymeric network. Thus, the size of the anion is crucial to obtain suitable single crystals of the material, as observed for $\left[\mathrm{Fe}(\mathrm{btzb})_{3}\right]^{2+}$. Surprisingly, crystalline compounds of $\left[\mathrm{Fe}(\mathrm{btzx})_{3}\right]^{2+}$ with three different counterions have been obtained that all exhibit spin-transition properties.

An evident effect of the counterion on the spin-transition properties concerns the remaining fraction of HS species at low temperatures, which is 10,50 and $80 \%$ for $\mathbf{1}-\mathbf{3}$, respectively. For $\left[\mathrm{Fe}(\mathrm{btzb})_{3}\right]\left[\mathrm{ClO}_{4}\right]_{2}$, the high fraction of HS iron centres at low temperatures has been assigned to a phase transition. ${ }^{[13]}$ In the case of compound 2, the structural phase transition and the spin crossover occur at different temperatures, suggesting that these two events are independent. This structural change may be responsible for the absence of $\mathrm{HS} \rightarrow \mathrm{LS}$ transition for some of the iron(II) centres. The variation of the anion-to-metal distance seems to affect the electronic properties of the iron(II) centres (see below). It has to be considered as well that the structural changes associated with the spin transition may restrict the number of $\mathrm{Fe}^{\mathrm{II}}$ ions undergoing the transition, as proposed for $\left[\mathrm{Fe}^{\mathrm{II}}-\right.$ $\left.(\text { btzpol })_{1.8}(\text { btzpol-OBF })_{1.2}\right]\left[\mathrm{BF}_{4}\right]_{0.8} \quad($ btzpol $=1,3$-bis $($ tetrazol1-yl)-2-propanol). ${ }^{[1]}$

The nature of the counterion has also an effect on the temperature of the spin transition $\left(T_{1 / 2}\right)$. Triazole-based materials have been intensively studied, and the influence of the different chemical "pieces" constituting the compound on the spin-transition properties has been thoroughly investigated. ${ }^{[37-42]}$ In the case of spherical counterions, the smallest ion leads to the highest transition temperature. ${ }^{[23]}$ The greater electrostatic pressure generated on the cation by the smaller anions, stabilises the LS state over the HS state. ${ }^{[23]}$ In the present case, the smaller perchlorate anion (compared to $\mathrm{PF}_{6}^{-}$) leads to a shift of the $\mathrm{T}_{1 / 2}$ value towards lower values. In contrast to previous examples, the smaller anion stabilises the HS state. Such behaviour has been observed in a few cases, reported by Long et al. and Tuchagues et al.. ${ }^{[3,44]}$ This was explained by steric interactions close to the metal centre that stabilise the HS state (shifting of $T_{1 / 2}$ towards lower temperatures). Bis(tetrazole)-based 1D polymers usually exhibit comparable crystal packings, in which the counterions are situated around the $\mathrm{Fe}^{\mathrm{II}}$ centres. The size and shape of the counterion will determine the anionto-metal distance. Thus, the use of smaller anions will result in shorter anion-to-metal distances, and will sterically limit the "tilting freedom" of the tetrazole rings. As a result, sterically hindered tetrazole rings give rise to low transition temperatures. Ultimately, these steric effects may annihilate the spin transition. ${ }^{[43,45]}$ This is observed for compound $\mathbf{2}$, in which the non-ST centres $\mathrm{Fe} 1$ and $\mathrm{Fe} 3$ exhibit shorter anion-to-metal distances, compared to the ST centres Fe2 and $\mathrm{Fe} 4$. An approximation to estimate the steric constraint around the metallic sphere consists in calculating the $\Sigma$ values. High $\Sigma$ values are associated with weaker crystal 
fields and therefore with the stabilisation of the HS state. ${ }^{[46]}$ As the ligand is monodentate, the only possible source of distortion is the anion. Based on the structural data available in the literature on bis(tetrazole) spin-transition compounds, a correlation between the anion-to-metal distance and the transition temperature is suggested (Figure 10 and Table 6). Long anion-to-metal distances are associated with small changes in the distortion of the octahedron during the spin transition (Figure 10).
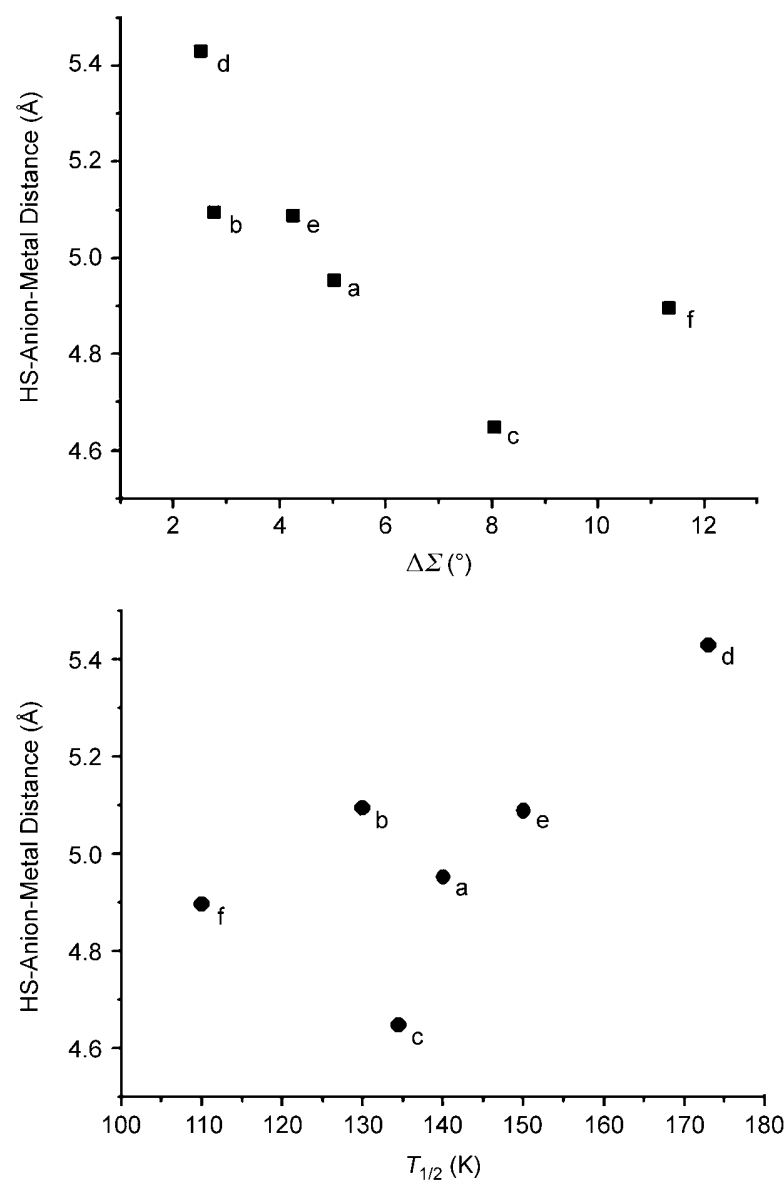

Figure 10. Top: $T_{1 / 2}$ (temperature at which $50 \%$ of the molecular complex is in the HS state) versus HS anion-to-metal distance. Bottom: Octahedral distortion versus HS anion-to-metal distance. See Table 6 for a-f labelling.

Table 6. Transition temperatures $\left(T_{1 / 2}\right)$, references for bis(tetrazole)based spin-transition compounds and the labels assigned to each compound for the data in Figure 10.

\begin{tabular}{llll}
\hline & $T_{1 / 2}[\mathrm{~K}]$ & Reference & $\begin{array}{l}\text { Label } \\
\text { (Figure 10) }\end{array}$ \\
\hline$\left[\mathrm{Fe}(\text { endi) })_{3}\right]\left[\mathrm{BF}_{4}\right]_{2}$ & 140 & {$[9]$} & $\mathrm{a}$ \\
{$\left[\mathrm{Fe}(\text { btzp })_{3}\right]\left[\mathrm{ClO}_{4}\right]_{2}$} & 130 & {$[14]$} & $\mathrm{b}$ \\
{$\left[\mathrm{Fe}(\text { btzmp) })_{2} \mu-(\text { btzmp })_{2}\right]\left[\mathrm{ClO}_{4}\right]_{2}$} & 135 & {$[10]$} & $\mathrm{c}$ \\
{$\left[\mathrm{Fe}(\mathrm{btzb})_{3}\right]\left[\mathrm{PF}_{6}\right]_{2}$} & 173 & {$[8]$} & $\mathrm{d}$ \\
{$\left[\mathrm{Fe}(\mathrm{btzx})_{3}\right]\left[\mathrm{PF}_{6}\right]_{2} \cdot \mathrm{CH}_{3} \mathrm{OH}(\mathbf{1})$} & 150 & this paper & $\mathrm{e}$ \\
{$\left[\mathrm{Fe}(\mathrm{btzx})_{3}\right]\left[\mathrm{CF}_{3} \mathrm{SO}_{3}\right]_{2} \cdot \mathrm{CH}_{3} \mathrm{CN}(\mathbf{2})$} & 110 & this paper & $\mathrm{f}$ \\
\hline
\end{tabular}

Interestingly, the cooperative nature of the spin transition has not been altered by the change of counterion. Indeed, both the triflate and the hexafluoridophosphate derivatives show similar slopes. The slightly less steep transition for the perchlorate compound is probably caused by the lower crystallinity of the material, which is known to affect the properties of the transition. ${ }^{[4,25]}$ This insignificant effect of the anions suggests that the cooperative nature of this cationic network arises from the intramolecular communication along the polymeric chains. Based on solid-state dilution studies that proved that the cooperativity is influenced by the number of ST centres in the material, ${ }^{[47]}$ the alternating distribution of the ST centres along the chains most likely affects the cooperativity within the system. Therefore, a more cooperative behaviour is expected for compound $\mathbf{1}$ (for which all $\mathrm{Fe}^{\mathrm{II}}$ centres are ST) than for $\mathbf{2}$ (which displays an alternating distribution of HS and ST centres). This is evidently not the case, as revealed by the similar transition curves obtained from magnetic susceptibility measurements for the two compounds. LITH experiments performed on compound 2 unambiguously indicate the presence of cooperative effects during the transition (Supporting Information). Thus, a plausible explanation for the gradual nature of the transition in this type of materials can be the involvement of internal constraints (short-range intramolecular interactions) that counterbalances the long-range cooperative interactions. ${ }^{[36]}$

Compounds $\mathbf{1}$ and $\mathbf{2}$ do differ in their LIESST properties. For compound $\mathbf{2}$ only the irradiation leads to the trapping of the high-spin metastable state. The $\chi_{\mathrm{m}} T$ value for the LIESST-generated $\mathrm{HS}$ metastable state of $\left[\mathrm{Fe}(\mathrm{btzx})_{3}\right]-$ $\left[\mathrm{CF}_{3} \mathrm{SO}_{3}\right]_{2}$ corresponds to the excitation of two iron(II) centres, namely $\mathrm{Fe} 2$ and $\mathrm{Fe} 4$. This metastable state relaxes back to the LS states with a $T$ (LIESST) of $54 \mathrm{~K}$. The stability of this metastable state depends on the cooperativity, as well as on the transition temperature. ${ }^{[4,48]}$ High $T_{1 / 2}$ are associated with lower energy barriers and faster relaxation to the LS state. For compound $\mathbf{1}$, the $T_{1 / 2}$ value is low enough and thus can not explain the absence of a HS metastable state. Recently, the distortion of the coordination sphere, $\Delta \theta$, has been related to the $T$ (LIESST) temperature. ${ }^{[49]}[\theta$ corresponds to the sum of the deviations from $60^{\circ}$ of the 24 possible $\theta$ angles.] High $\Delta \theta$ values result in higher $T$ (LIESST) temperatures. The $\Delta \Sigma$ values corresponding to complexes $\mathbf{1}$ and 2 allow to compare the respective octahedral distortions. ${ }^{[50]}$ In this case, the octahedral distortion for compound $\mathbf{1}$ is much smaller than that observed for the atoms Fe 2 and $\mathrm{Fe} 4$ of compound 2. These distinct geometric distortions may be responsible for the different photomagnetic behaviour.

\section{Conclusion}

The series of compounds $\left[\mathrm{Fe}(\mathrm{btzx})_{3}\right]\left[\mathrm{PF}_{6}\right]_{2} \cdot \mathrm{CH}_{3} \mathrm{OH}$ (1), $\left[\mathrm{Fe}(\mathrm{btzx})_{3}\right]\left[\mathrm{CF}_{3} \mathrm{SO}_{3}\right]_{2} \cdot \mathrm{CH}_{3} \mathrm{CN}$ (2) and $\left[\mathrm{Fe}(\mathrm{btzx})_{3}\right]-$ $\left[\mathrm{ClO}_{4}\right]_{2} \cdot \mathrm{CH}_{3} \mathrm{CN}(\mathbf{3})$ has clearly shown the template role of 
the counterions, which determines the spin-transition properties, and allowed the first structural characterisation of an HS-LS alternating coordination chain. Short anion-to-metal distances lead to significant distortions of the octahedral coordination environment of the iron(II) centres, resulting in lower temperatures for the spin transition. For the $[\mathrm{Fe}$ $\left.(\text { btzx })_{3}\right]^{2+}$ ion several structural features, that is, $\Delta \Sigma$, the cone angle and the (tetrazole-centroid) $-\mathrm{N}_{\mathrm{D}}-\mathrm{Fe}$ angle, reflect the steric hindrance around the $\mathrm{Fe}^{\mathrm{II}}$ centre. These features are all associated with the size and shape of the counterions, as well as their position in the lattice. The HS fraction remaining at low temperatures is also linked to the distortion of the octahedron. Apparently, for a certain degree of distortion, the $\mathrm{Fe}^{\mathrm{II}}$ ion remains in HS state through the whole temperature range. This is observed for the triflate derivative, the two HS centres of which show the highest distortions of the octahedron. The cooperative nature of the cationic species barely depends on the nature of the anion used, suggesting that the nature of the cooperativity is intrapolymeric. This observation is in contradiction with the fact that the alternating distribution of the ST centres in the 1D chains ( $\cdots$ HS-LS-HS $\cdots$ ) of the triflate derivative does not affect the cooperative nature of the $\left[\mathrm{Fe}(\mathrm{btzx})_{3}\right]^{2+}$-based material. Compounds $\mathbf{1}$ and $\mathbf{2}$ also differ in their LIESST properties. Only the HS metastable state of the compound $\mathbf{2}$ can be trapped under light irradiation. The origin of this disparity is not fully understood, but the greater distortion of the octahedral environment around the $\mathrm{Fe}^{\mathrm{II}}$ centres of compound 2 appears to be critical. Further structural analysis, including optical and pressure dependent studies, are necessary for a better understanding of this cationic system.

\section{Experimental Section}

Elemental analysis: Elemental analyses (C, H, N, S) were performed on a Perkin-Elmer 2400 series II at the Gorlaeus Laboratories.

UV/Vis spectroscopy: UV/Vis spectra were obtained on a Perkin-Elmer Lambda 900 spectrophotometer by using the diffuse reflectance technique, with $\mathrm{MgO}$ as a reference. A sample holder mounted on a Dewar and in thermal contact with the refrigerant through a copper rod was used to perform measurements at temperatures around $100 \mathrm{~K}$. The spectral range used was $200-1200 \mathrm{~nm}$. All samples, crystalline or powder, were crushed when placed in the sample holder.

Magnetic susceptibility measurements: Magnetic susceptibility measurements were carried out on a Quantum Design MPMS-5S SQUID magnetometer. The SQUID probes the total magnetisation of the sample by measuring the induced currents in a Josephson junction when moving the sample in between coils. The accessible field is up to $5 \mathrm{~T}$, and the temperature ranges from 1.8 to $400 \mathrm{~K}$. The data were measured at $1000 \mathrm{G}$ from 4 to $300 \mathrm{~K}$. Data were corrected for magnetisation of the sample holder and for the diamagnetic contributions, which were estimated from the Pascal's tables. ${ }^{[51]}$ Samples made out of single crystals were gently crushed prior to measurement.

Mössbauer spectroscopy: Mössbauer data were recorded on a spectrometer with alternating constant acceleration. The minimum experimental line width was $0.24 \mathrm{mms}^{-1}$ (full width at half-height). The sample temperature was maintained in an Oxford Instrument Variox cryostat and the ${ }^{57} \mathrm{Co} / \mathrm{Rh}$ source $(1.8 \mathrm{GBq})$ was at room temperature. Isomer shifts are quoted relative to iron metal at $300 \mathrm{~K}$.
X-ray data for $\left[\mathbf{F e}(\mathbf{b t z x})_{3}\right]\left[\mathbf{P F}_{6}\right]_{2} \cdot \mathbf{M e O H}(1)$ : X-ray data were collected at $200 \mathrm{~K}$ and $100 \mathrm{~K}$, respectively, on a Nonius KappaCCD diffractometer on rotating anode with graphite-monochromated $\mathrm{Mo}_{\mathrm{K} \alpha}$ radiation $(\lambda=$ $0.71073 \AA$ ). The structures were solved with direct methods using SHELXS $86^{[52]}$ and refined on $F^{2}$ with SHELXL-97. ${ }^{[53]}$ The hydrogen atoms were included in the refinement at calculated positions and refined riding on the atoms to which they are attached with standard SHELXL97 geometry and isotropic displacement parameter constraints. ${ }^{[53]}$ The methanol inclusion solvent molecule was included with a disorder model. Both the carbon and the oxygen atoms of the methanol molecule were disordered in two positions with an occupational factor of 0.5 .

$\mathrm{X}$-ray data for $\left[\mathrm{Fe}(\mathrm{btzx})_{3}\right]\left[\mathrm{CF}_{3} \mathrm{SO}_{3}\right]_{2} \cdot \mathrm{CH}_{3} \mathrm{CN}$ (2): X-ray data were collected at $170 \mathrm{~K}$ and $100 \mathrm{~K}$ respectively on a Nonius KappaCCD diffractometer on rotating anode with graphite-monochromated $\mathrm{Mo}_{\mathrm{K} \alpha}$ radiation $(\lambda=$ $0.71073 \AA$ ). The structures were solved with direct methods using SHELXS $86^{[52]}$ and refined on $F^{2}$ with SHELXL-97. ${ }^{[53]}$ The hydrogen atoms were included in the refinement at calculated positions and refined riding on the atoms to which they are attached with standard SHELXL97 geometry and isotropic displacement parameter constraints. ${ }^{[33]}$ The crystals are merohedrally twinned (matrix: [-100/0-10/001]) with twin fraction $\approx 50: 50$. Merohedral twinning is a special case of crystallographic twinning where the lattices of twin (different) domains (in a single crystal) overlap in three dimensions. For instance, two domains in which one of them is rotated $180^{\circ}$ with respect to the other.

Synthesis of $\boldsymbol{m}$-xylylene(bis)tetrazole (btzx): $m$-Xylylenediamine( $5 \mathrm{~g}$, $0.037 \mathrm{~mol})$, triethylorthoformate $(54 \mathrm{~g}, 0.363 \mathrm{~mol})$ and sodium azide $(4.79 \mathrm{~g}, 0.074 \mathrm{~mol})$ were dissolved in acetic acid $(90 \mathrm{~mL})$ and heated at $90^{\circ} \mathrm{C}$ for $2 \mathrm{~d}$. After cooling down to room temperature, the solvent was evaporated under reduced pressure. The remaining yellow solid was washed with methanol and water yielding the ligand as a white powder. Yield $=64 \% ;{ }^{1} \mathrm{H}$ NMR $\left(300 \mathrm{MHz},\left[\mathrm{D}_{6}\right] \mathrm{DMSO}\right): \delta=5.7\left(\mathrm{~s}, 4 \mathrm{H} ;\right.$ ttz- $\mathrm{CH}_{2^{-}}$ ph), 7.4 (m, 4H; ph), 9.5 ppm (s, $2 \mathrm{H}$; ttz); IR: $\tilde{v}=3116.5 \mathrm{~cm}^{-1}\left(v_{\mathrm{Cttz}-\mathrm{H}}\right)$; elemental analysis calcd (\%) for $\mathrm{C}_{10} \mathrm{H}_{10} \mathrm{~N}_{8}$ : C 49.58, H, 4.16, N 46.26; found: C 49.09, H 4.13, N 45.59.

Synthesis of $\left[\mathbf{F e}(\mathbf{b t z x})_{3}\right]\left[\mathrm{PF}_{6}\right]_{2} \cdot \mathbf{M e O H}(1)$ : One equivalent of btzx (50 mg, $0.21 \mathrm{mmol})$ and two equivalents of $\mathrm{NH}_{4} \mathrm{PF}_{6}(68.5 \mathrm{mg}, 0.42 \mathrm{mmol})$ dissolved in dry methanol $(10 \mathrm{~mL})$ were added to one equivalent of $\mathrm{FeCl}_{2} \cdot 4 \mathrm{H}_{2} \mathrm{O}(41.5 \mathrm{mg}, 0.21 \mathrm{mmol})$ dissolved in dry methanol $(5 \mathrm{~mL})$, containing ascorbic acid (ca. $20 \mathrm{mg}$ ) and triethylorthoformate $(3 \mathrm{~mL})$. The resulting solution was heated for an hour at $50^{\circ} \mathrm{C}$. A white crystalline solid appeared after approximately $4 \mathrm{~d}$, through the slow evaporation of the solvent at room temperature. The crystals were washed with methanol. Yield $=30 \%$; IR: $\tilde{v}=3160\left(v_{\mathrm{Cttz}-\mathrm{H}}\right), 833 \mathrm{~cm}^{-1}\left(v_{\mathrm{P}-\mathrm{F}}\right)$; elemental analysis calcd (\%) for $\mathrm{C}_{31} \mathrm{H}_{34} \mathrm{~F}_{12} \mathrm{FeN}_{24} \mathrm{OP}_{2}$ : C 33.71, H 3.10; N 30.43; found: C 33.81, H 3.34, N 30.11.

Synthesis of $\left[\mathrm{Fe}(\mathrm{btzx})_{3}\right]\left[\mathrm{CF}_{3} \mathrm{SO}_{3}\right]_{2} \cdot \mathrm{CH}_{3} \mathrm{CN}$ (2): Three equivalents of btzx $(50 \mathrm{mg}, 0.21 \mathrm{mmol})$ dissolved in acetonitrile $(5 \mathrm{~mL})$ were added to one equivalent of $\mathrm{Fe}\left(\mathrm{CF}_{3} \mathrm{SO}_{3}\right)_{2} \cdot 6 \mathrm{H}_{2} \mathrm{O}(32.3 \mathrm{mg}, 0.07 \mathrm{mmol})$ dissolved in acetonitrile $(5 \mathrm{~mL})$ containing ascorbic acid (ca. $20 \mathrm{mg}$ ). The solution was heated for an hour at $50^{\circ} \mathrm{C}$. The solution was then placed in a tube and diethyl ether was added until a light white precipitate had formed. Next, the tube was capped and left unperturbed for $2-3 \mathrm{~h}$. Transparent single crystals appeared on the walls of the tube. The crystals were then washed with acetonitrile. Yield $=56 \%$; IR $\tilde{v}=3112\left(v_{\mathrm{Ctt}-\mathrm{H}}\right), 1265,1233\left(v_{\mathrm{C}-\mathrm{F}}\right)$, 1145, $1035 \mathrm{~cm}^{-1} \quad\left(v_{\mathrm{S}-\mathrm{O}}\right)$; elemental analysis calcd $(\%)$ for $\mathrm{C}_{34} \mathrm{H}_{33} \mathrm{~F}_{6} \mathrm{FeN}_{25} \mathrm{O}_{6} \mathrm{~S}_{2}$ : C 36.4, H 2.97, N 31.22; found: C 35.94, H 3.03, N 30.67 .

Synthesis of $\left[\mathrm{Fe}(\mathrm{btzx})_{3}\right]\left[\mathrm{ClO}_{4}\right]_{2} \cdot \mathrm{CH}_{3} \mathrm{CN}$ (3): Three equivalents of btzx $(100 \mathrm{mg}, 0.41 \mathrm{mmol})$ were dissolved in acetonitrile $(15 \mathrm{~mL})$. A solution of one equivalent of $\mathrm{Fe}\left(\mathrm{ClO}_{4}\right)_{2}(35 \mathrm{mg}, 0.14 \mathrm{mmol})$ in acetonitrile $(15 \mathrm{~mL})$ was added to the ligand solution. The resulting transparent solution was heated for $2 \mathrm{~h}$ and filtered. The filtrate was left unperturbed to allow the slow evaporation of the solvent. A white crystalline powder appeared after a few days. This solid material was filtered and washed with acetonitrile. Yield $=40 \%$; IR: $\tilde{v}=1080.3,1354.7,1435.5,1505.4,3136.3 \mathrm{~cm}^{-1}$; elemental analysis calcd (\%) for $\mathrm{C}_{32} \mathrm{H}_{33} \mathrm{Cl}_{2} \mathrm{FeN}_{25} \mathrm{O}_{8}$ : C 37.59, H 3.25, N 34.25; found: C 37.29, H 3.01, N 33.95 . 


\section{Acknowledgements}

The work described here has been supported by the Leiden University Study group WFMO (Werkgroep Fundamenteel Materialen-Onderzoek). COST Action D35/0011 and coordination by the FP6 Network of Excellence "Magmanet" (contract number 515767) are also kindly acknowledged. The authors acknowledge provision of time on beamline 11.3.1 of the Advanced Light Source synchrotron.

[1] "Towards Spin Crossover Applications": J. F. Létard, P. Guionneau, L. Goux-Capes, Top. Curr. Chem. 2004, 235, 221-249.

[2] O. Kahn, J. Kröber, C. Jay, Adv. Mater. 1992, 4, 718-728.

[3] O. Kahn, C. J. Martinez, Science 1998, 279, 44-48.

[4] P. Gütlich, A. Hauser, H. Spiering, Angew. Chem. 1994, 106, 21092141; Angew. Chem. Int. Ed. Engl. 1994, 33, 2024-2054.

[5] M. Sorai, S. Seki, J. Phys. Chem. Solids 1974, 35, 555-570.

[6] "Special Classes of Iron(II) Azole Spin Crossover Compounds": P. J. van Koningsbruggen, Top. Curr. Chem 2004, 233, 123-149.

[7] P. J. van Koningsbruggen, M. Grunert, P. Weinberger, Monatsh. Chem. 2003, 134, 183-198.

[8] C. M. Grunert, J. Schweifer, P. Weinberger, W. Linert, K. Mereiter, G. Hilscher, M. Müller, G. Wiesinger, P. J. van Koningsbruggen, Inorg. Chem. 2004, 43, 155-165.

[9] M. P. F. Quesada, O. Roubeau, P. Gamez, S. J. Taet, P. J. van Konningsbruggen, J. G. Haasnoot, J. Reedijk, Inorg. Chim. Acta 2007, 360, 3787-3796.

[10] J. Schweifer, P. Weinberger, K. Mereiter, M. Boca, C. Reichl, G. Wiesinger, G. Hilscher, P. J. van Koningsbruggen, H. Kooijman, M. Grunert, W. Linert, Inorg. Chim. Acta 2002, 339, 297-306.

[11] M. Quesada, H. Kooijman, P. Gamez, J. S. Costa, P. J. Van Koningsbruggen, P. Weinberger, M. Reissner, A. L. Spek, J. G. Haasnoot, J. Reedijk, Dalton Trans. 2007, 46, 5434-5440.

[12] A. Absmeier, M. Bartel, C. Carbonera, G. N. L. Jameson, P. Weinberger, A. Caneschi, K. Mereiter, J. F. Létard, W. Linert, Chem. Eur. J. 2006, 12, 2235-2243.

[13] P. J. van Koningsbruggen, Y. Garcia, H. Kooijman, A. L. Spek, J. G. Haasnoot, O. Kahn, J. Linarès, E. Codjovi, F. Varret, J. Chem. Soc. Dalton Trans. 2001, 466-471.

[14] R. Bronisz, Inorg. Chim. Acta 2004, 357, 396-404.

[15] P. J. van Koningsbruggen, Y. Garcia, O. Kahn, L. Fournès, H. Kooijman, A. L. Spek, J. G. Haasnoot, J. Moscovici, K. Provost, A. Michalowicz, F. Renz, P. Gütlich, Inorg. Chem. 2000, 39, 1891-1900.

[16] S. Alvarez, J. Am. Chem. Soc. 2003, 125, 6795-6802.

[17] M. Quesada, Spin-Transition Frameworks based on Bis(tetrazole) and Triazine Ligands, Ph.D. Thesis, Leiden University, Leiden, 2007.

[18] P. J. van Koningsbruggen, Y. Garcia, G. Bravic, D. Chasseau, O. Kahn, Inorg. Chim. Acta 2001, 326, 101-105.

[19] A. B. Gaspar, M. C. Muñoz, J.A. Real, J. Mater. Chem. 2006, 16, 2522-2533.

[20] Y. Garcia, O. Kahn, L. Rabardel, B. Chansou, L. Salmon, J. P. Tuchagues, Inorg. Chem. 1999, 38, 4663-4670.

[21] V. Niel, A. L. Thompson, A. E. Goeta, C. Enachescu, A. Hauser, A. Galet, M. C. Muñoz, J. A. Real, Chem. Eur. J. 2005, 11, 2047-2060.

[22] O. Roubeau, Solid State Properties of Triazole-Based Fe ${ }^{I I}$ Materials, Ph.D. Thesis, Leiden University, Leiden, 2002.

[23] O. Roubeau, J. M. A. Gomez, E. Balskus, J. J. A. Kolnaar, J. G. Haasnoot, J. Reedijk, New J. Chem. 2001, 25, 144-150.

[24] M. Yamada, H. Hagiwara, H. Torigoe, N. Matsumoto, M. Kojima, F. Dahan, J. P. Tuchagues, N. Re, S. Iijima, Chem. Eur. J. 2006, 12, 4536-4549.

[25] M. S. Haddad, W. D. Federer, M. W. Lynch, D. N. Hendrickson, Inorg. Chem. 1981, 20, 131-139.
[26] S. Decurtins, P. Gütlich, C. P. Köhler, H. Spiering, A. Hauser, Chem. Phys. Lett. 1984, 105, 1-4.

[27] J. F. Létard, P. Guionneau, L. Rabardel, J.A.K. Howard, A. E. Goeta, D. Chasseau, O. Kahn, Inorg. Chem. 1998, 37, 4432-4441.

[28] C. Roux, J. Zarembowitch, B. Gallois, T. Granier, R. Claude, Inorg. Chem. 1994, 33, 2273-2279.

[29] J. A. Real, H. Bolvin, A. Bousseksou, A. Dworkin, O. Kahn, F. Varret, J. Zarembowitch, J. Am. Chem. Soc. 1992, 114, 4650-4658.

[30] "Bipyrimidine-Bridged Dinuclear Iron(II) Spin Crossover Compounds": J. A. Real, A. B. Gaspar, M. C. Muñoz, P. Gütlich, V. Ksenofontov, H. Spiering, Top. Curr. Chem 2004, 233, 167-193.

[31] N. Ortega-Villar, A. L. Thompson, M. C. Muñoz, V. M. Ugalde-Saldivar, A. E. Goeta, R. Moreno-Esparza, J.A. Real, Chem. Eur. J. 2005, 11, 5721-5734.

[32] V. Ksenofontov, A. B. Gaspar, V. Niel, S. Reiman, J. A. Real, P. Gütlich, Chem. Eur. J. 2004, 10, 1291-1298.

[33] S. Zein, S. A. Borshch, J. Am. Chem. Soc. 2005, 127, 16197-16201.

[34] M. Sorai, J. Ensling, P. Gütlich, Chem. Phys. 1976, 18, 199-209.

[35] D. Chernyshov, M. Hostettler, K. W. Tornroos, H. B. Burgi, Angew. Chem. 2003, 115, 3955-3960; Angew. Chem. Int. Ed. 2003, 42, $3825-$ 3830 .

[36] E. Breuning, M. Ruben, J. M. Lehn, F. Renz, Y. Garcia, V. Ksenofontov, P. Gutlich, E. Wegelius, K. Rissanen, Angew. Chem. 2000, 112, 2563-2566; Angew. Chem. Int. Ed. 2000, 39, 2504-2507.

[37] Y. Garcia, P. J. van Koningsbruggen, R. Lapouyade, L. Fournès, L. Rabardel, O. Kahn, V. Ksenofontov, G. Levchenko, P. Gütlich, Chem. Mater. 1998, 10, 2426-2433.

[38] J. G. Haasnoot, Coord. Chem. Rev. 2000, 200, 131-185.

[39] C. Jay, F. Grolière, O. Kahn, J. Kröber, Mol. Cryst. Liq. Cryst. Sci. Technol. Sect. A 1993, 234, 255-262.

[40] O. Kahn, E. Codjovi, Philos. Trans. R. Soc. London Ser. A 1996, 354, 359-379.

[41] L. G. Lavrenova, V. N. Ikorskii, V. A. Varnek, I. M. Oglezneva, S. V. Larionov, J. Struct. Chem. 1993, 34, 960-965.

[42] L. G. Lavrenova, N. G. Yudina, V. N. Ikorskii, V. A. Varnek, I. M. Oglezneva, S. V. Larionov, Polyhedron 1995, 14, 1333-1337.

[43] "Spin Crossover in Pyrazolylborate and Pyrazolylmethane Complexes": G. J. Long, F. Grandjean, D. L. Reger, Top. Curr. Chem 2004, 233, 91-122.

[44] M. Yamada, M. Ooidemizu, Y. Ikuta, S. Osa, N. Matsumoto, S. Iijima, M. Kojima, F. Dahan, J.-P. Tuchagues, Inorg. Chem. 2003, 42, 8406-8416.

[45] D. L. Reger, J. R. Gardinier, M. D. Smith, A. M. Shahin, G. J. Long, L. Rebbouh, F. Grandjean, Inorg. Chem. 2005, 44, 1852-1866.

[46] P. Guionneau, C. Brigouleix, Y. Barrans, A. E. Goeta, J. F. Letard, J. A. K. Howard, J. Gaultier, D. Chasseau, C. R. Acad. Sci. Ser. IIc 2001, 4, 161-171.

[47] A. Hauser, P. Gütlich, H. Spiering, Inorg. Chem. 1986, 25, 42454248.

[48] "Light-Induced Spin Crossover and the High-Spin $\rightarrow$ Low-Spin Relaxation": A. Hauser, Top. Curr. Chem 2004, 234, 155-198.

[49] M. Marchivie, P. Guionneau, J. F. Létard, D. Chasseau, Acta Crystallogr. Sect. B 2005, 61, 25-28.

[50] "Structural Aspects of Spin Crossover-Example of the [(FeLn)-LII(NCS)(2)] Complexes": P. Guionneau, M. Marchivie, G. Bravic, J. F. Létard, D. Chasseau, Top. Curr. Chem 2004, 234, 97-128.

[51] O. Kahn, Molecular Magnetism in Molecular Magnetism, VCH, Weinheim, 1993, p. 131.

[52] G. M. Sheldrick, SHELXS86, University of Göttingen, 1986.

[53] G. M. Sheldrick, SHELXL-97, Program for Crystal Structure Refinement, University of Göttingen, 1997. 